\title{
A techno-economic assessment of implementing power-to-gas systems based on biomethanation in an operating waste water treatment plant
}

\author{
Stavros Michailos ${ }^{\mathrm{a},}{ }^{,}$, Mark Walker $^{\mathrm{b}}$, Adam Moody $^{\mathrm{c}}$, Davide Poggio ${ }^{\mathrm{a}}$, Mohamed \\ Pourkashanian $^{\mathrm{a}}$
}

\begin{abstract}
aEnergy 2050, Department of Mechanical Engineering, Faculty of Engineering, University of Sheffield, Sheffield S3 7RD, UK.

${ }^{b}$ Environmental Research Institute, North Highlands College, University of the Highlands and Islands Thurso KW14 7EE, UK.

'United Utilities Group PLC, Haweswater House, Lingley Mere Business Park, Lingley Green Avenue, Great Sankey, Warrington, WA5 3LP, UK.
\end{abstract}

Abstract. The aim of the present study is to assess the techno-economic viability of integrating biomethanation into power to gas systems in a real waste water treatment plant (WWTP). The research is the first attempt to assess the viability of several scenarios based on the biomethanation technology that include both in- and ex-situ biomethanation as well as utilisation of on-site renewable electricity and grid electricity in a transient mode.

Five scenarios were designed and evaluated and the calculated LCOE lies between 127.8 and 159.8 $\mathrm{f} / \mathrm{MWh}$. The consideration of existing policy mechanisms and revenues from by-products reduces the LCOEs to $31.4-68.1 \mathrm{f} / \mathrm{MWh}$. The execution of a sensitivity analysis exposed that the electricity price and the electrolyser cost are the main cost contributors in all the scenarios. Future techno-economic advances along with imposing appropriate policy incentives can create the proper framework for two scenarios to generate profits. The study concludes that current and future power to gas application should focus on utilising on-site generated electricity.

Keywords: biomethanation; power to gas; biogas upgrading; $\mathrm{CO}_{2}$ utilisation; techno-economics; carbon footprint assessment 


\section{Introduction}

Anaerobic digestion is an efficient technology that can convert organic wastes and energy crops to a valuable energy carrier known as biogas [1]. Biogas is a mixture of methane, carbon dioxide and impurities such as hydrogen sulphide, ammonia and siloxanes [2]. Aside from methane, all the other compounds are undesirable and are measured as biogas pollutants. Furthermore, if not upgraded, biogas applications are limited to local/on-site CHP generation [3]. On the other hand, biogas can be upgraded to biomethane that is a more flexible fuel, has higher energy density, can be injected into the natural gas grid and has multiple applications including road transport [4]. Additionally, it has been conveyed that a substantial potential in primary energy savings for national economies occurs if biogas from large scale plants is to be upgraded to biomethane for replacing fossil fuels in lieu of exploiting it for generating renewable electricity [5]. In numerous countries, biogas plants are anticipated to shift from electricity generation to biomethane production, on condition that adequate policy support is offered [4]. Therefore, the upgrade of biogas to biomethane has received significant interest with many commercial biomethane plants being already in operation as depicted in Figure 1 [6].

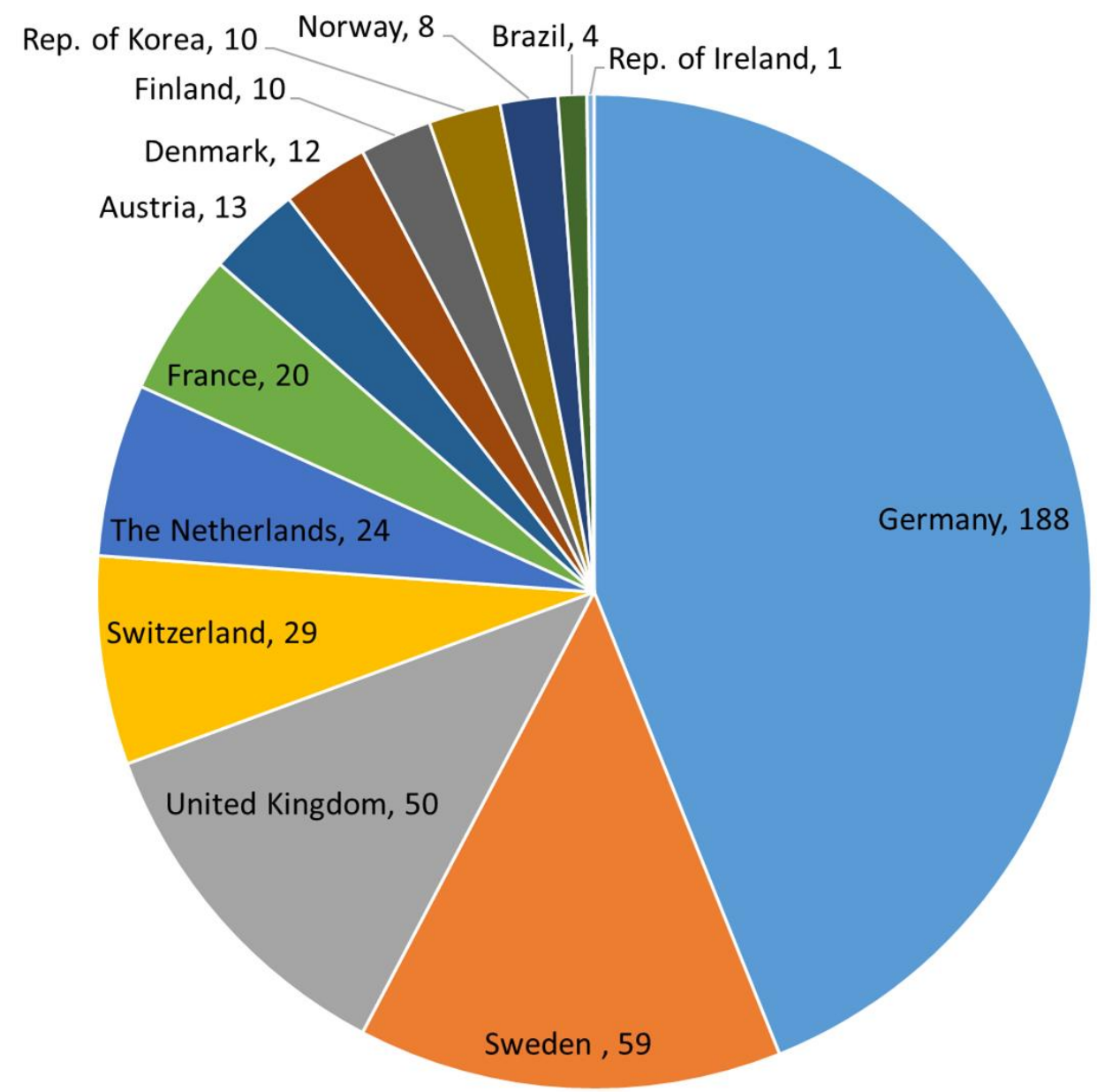

Figure 1. The distribution of operational biogas upgrading units among the IEA Bioenergy Task 37 member countries [6]. 
Several biogas upgrading technologies exist in the market including physical absorption (water or organic), chemical absorption, pressure swing adsorption (PSA), membrane and cryogenic [7]. All these technologies remove $\mathrm{CO}_{2}$ from the biogas and subsequently vent it to the atmosphere. An emerging way to upgrade biogas is through the Power to Gas (P2G) concept. The latter involves the supply of electric power to electrolyse water and subsequently the conversion of hydrogen and $\mathrm{CO}_{2}$ to $\mathrm{CH}_{4}$ via the Sabatier reaction, Eq. (1) [8]. In this way, the biomethane yield significantly increases and within the boundaries of the plant a near-zero $\mathrm{CO}_{2}$ emission process can be established, when carbon conversion approaches $100 \%$ in the upgrading process. In addition, the P2G can store excess renewable energy as a gaseous fuel for longer periods and at a larger scale than battery storage and provide ancillary services to the electricity grid. Despite that a P2G system producing methane instead of hydrogen achieves lower thermodynamic efficiency, the predominant gas grids are intended to accommodate methane distribution and the direct injection of hydrogen is limited and therefore methane may be a fitter and more effective alternative until the gas infrastructure is upgraded [8].

$\mathrm{CO}_{2}+4 \mathrm{H}_{2} \rightarrow \mathrm{CH}_{4}+2 \mathrm{H}_{2} \mathrm{O}, \Delta \mathrm{H}^{0}=-165 \mathrm{~kJ} / \mathrm{mol}$

As depicted in Table 1 [8], according to recent forecast estimates there is huge potential for renewable gas production. The report prepared by the European Natural \& Bio Gas Vehicle Association (NGVA) identifies the medium-term implementation of P2G applications as a key factor in decarbonising the energy sector and this in turn highlights the importance of further research on P2G systems.

Table 1. Production forecasts for renewable gas by NGVA [8].

\begin{tabular}{lcc}
\hline$[\mathrm{bcm} / \mathrm{y}]$ & $\mathbf{2 0 1 7}$ & $\mathbf{2 0 3 0}$ \\
\hline $\mathrm{AD}$ & 1.8 & $13-19$ \\
$\mathrm{P} 2 \mathrm{G}^{*}$ & $810^{-3}$ & $11-16$ \\
$\mathrm{SNG} * *$ & $310^{-6}$ & $12-16$ \\
Total & 1.8 & $36-51$ \\
\hline${ }^{*}$ P2G refers to natural gas from electricity and $\mathrm{CO}_{2}$ & \\
${ }^{* *}$ Synthetic Natural Gas from biomass gasification & \\
\hline
\end{tabular}

The Sabatier reaction can be accomplished either chemically or biologically. Compared to the chemical synthesis process, biological methanation (biomethanation) is more tolerant to biogas impurities such as siloxanes and operates at significantly milder process conditions (e.g. temperature and pressure) [9]. Additionally, the adjustment of the reactor design to the specifications of the biomethanation is easier and it has been also suggested that biomethanation is more suitable for small-scale applications including the conversion of biogas contained $\mathrm{CO}_{2}[10]$. Despite that biomethanation has a lower TRL than the chemical synthesis, there exist pilot plants that currently investigate the feasibility of 
biomethanation such as the MicrobEnergy plant in Schwandorf and the BioCat project in Copenhagen because of the aforementioned advantages; in both cases the $\mathrm{CO}_{2}$ source is biogas [11].

Technoeconomic assessment (TEA) of emerging technologies such as biomethanation can provide meaningful insights, identify key cost drives and justify R\&D support [12]. Even if there is a plethora of TEA regarding the chemical synthesis [13][14][15][16][17][18][19], existing data in the literature with respect to the biomethanation is more limited. In the past, only few studies have studied the financial viability of biomethanation [20][21][22][23]. All of them investigated the ex-situ configuration whereby biomethanation takes place in a separate from the digester reactor. Additionally, these studies have only explored the feasibility of a sole assembly of components excluding from the analysis the combination of different equipment components and the evaluation of different operational strategies. To this end, the current research undertakes a comprehensive TEA of various process designs that include both ex- and in-situ biomethanation, different types of electrolysers as well as both dynamic and continuous operation. This is the first attempt to explore in a holistic manner the feasibility of biomethanation and identify the most suitable configuration.

\section{Research outline}

\subsection{Definition of scenarios}

The business as usual model for a wastewater treatment plant (WWTP) includes the digestion of sewage sludge for waste management purposes and electricity generation from biogas. The current study deals with retrofit designs and assumes that the biogas is upgraded through biomethanation. For the economic evaluation, the boundaries include only the electrolyser and the biomethanation system. Also, an opportunity loss is included as the electricity that used to be generated from the biogas (i.e. 2.6 MW in this study) in the business as usual model, it is now imported, in the retrofit scenarios, either from the grid or renewable sources depending on the scenario.; the calculation of the lost electricity is based on a 40\% HHV electrical efficiency. On the other hand, the technical design includes the mass balances around the digesters as all additional equipment is sized based on the biogas produced.

As depicted in Figure 2, five different biomethanation scenarios were designed and investigated; these are also described in Table 2. As mentioned before, the study explores a variety of possible biomethanation based P2G implementations. As such, the scenarios differ based on a) technologies: ex- or in-situ biomethanation, proton exchange membrane electrolysis (PEMEL) or alkaline electrolysis $(A E L), b)$ electricity procurement: grid connection or dedicated wind turbines for on-site electricity generation and c) operation: dynamic based on the hourly spot electricity prices of UK or continuous operation. The focus of the study is the in-situ biomethanation as no techno-economic assessment for 
this configuration exists in the literature. In addition, it should be noted that all scenarios were designed in such a manner so as to generate the same amount of biomethane, i.e. 10.60 MW (HHV basis), based on the methane produced through the digestion process plus the methane produced by biomethanation.

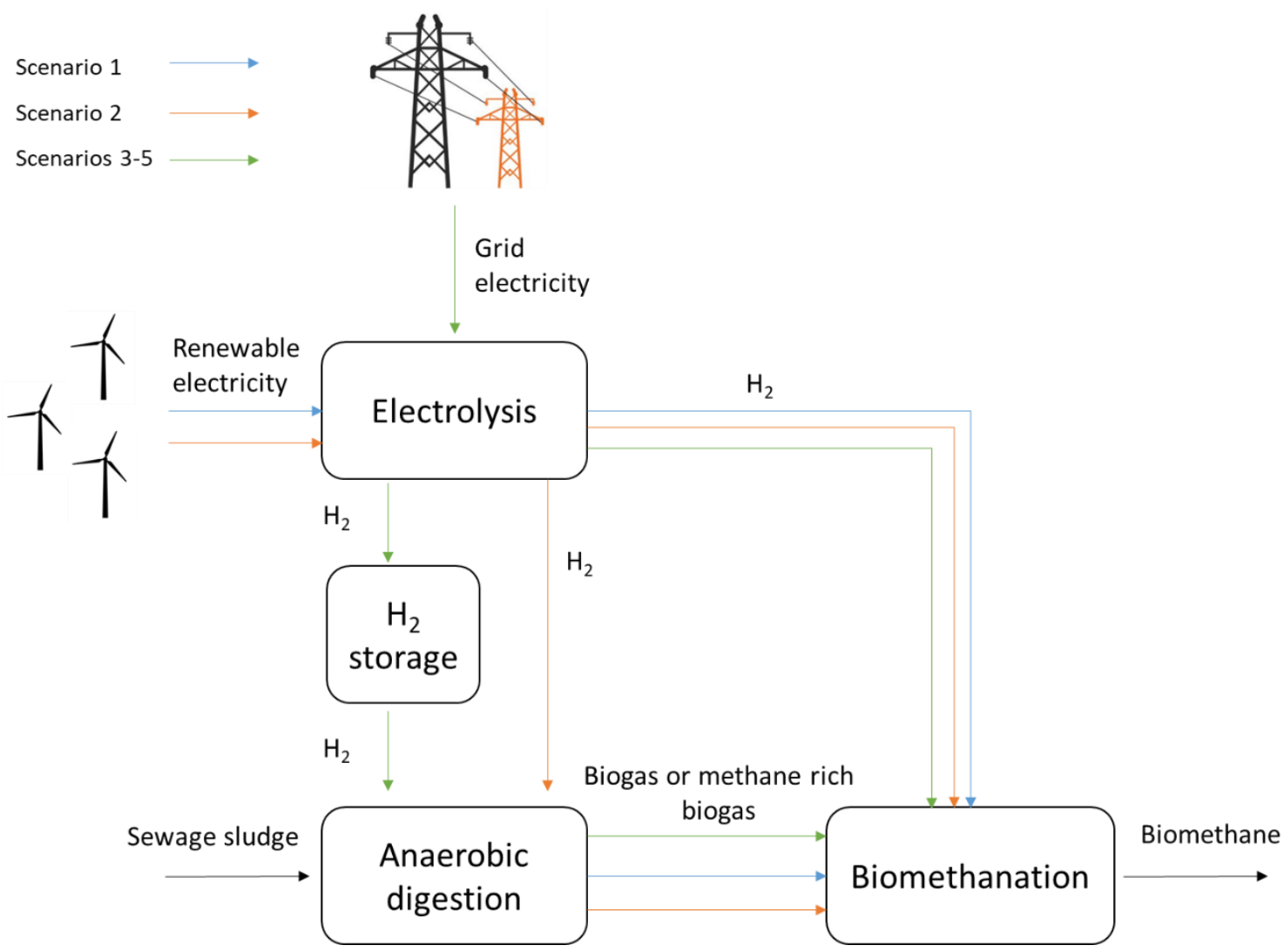

Figure 2. System boundaries of the examined biomethanation scenarios.

Table 2. Description of the scenarios developed and investigated in the present study.

\section{Scenario Description}

Scenario 1 Ex situ biomethanation coupled with AEL (continuous operation) and on-site electricity generation; the electrolyser size is $7.45 \mathrm{MW}$.

Scenario 2 In situ biomethanation coupled with AEL (continuous operation) and on-site electricity generation; the electrolyser size is $7.45 \mathrm{MW}$.

Scenario 3 In situ biomethanation coupled with PEMEL and operating dynamically when electricity price is below $50 \mathrm{f} / \mathrm{MWh}$; the electrolyser size is $10.11 \mathrm{MW}$.

Scenario 4 In situ biomethanation coupled with PEMEL and operating dynamically when electricity price is below $40 \mathrm{f} / \mathrm{MWh}$; the electrolyser size is $12.95 \mathrm{MW}$.

Scenario 5 In situ biomethanation coupled with PEMEL and operating dynamically when electricity price is below $30 \mathrm{f} / \mathrm{MWh}$; the electrolyser size is $18.67 \mathrm{MW}$.

electrolyser sizes are expressed as electrical power input 
From a conceptual point a view, in-situ biomethanation appears to be more attractive than the ex-situ configuration since no additional reactor is necessary. Nevertheless, full conversion of $\mathrm{CO}_{2}$ in the digester is a challenge as this practice can distort the bicarbonate equilibrium and increase the $\mathrm{pH}$; an event that inhibits the methanogenic activity [24]. On top of this, mass transfer limitations also hinder the full conversion of $\mathrm{CO}_{2}$. Reported methane concentrations can reach up to 95\% [24][25]. In this study a more conservative and probably more realistic for larger scale applications value was assumed where the final composition of biogas exiting the digesters is taken as $90 \%$ methane. In these cases (scenarios 2-5), an additional step is required to meet the natural gas grid requirements. We consider that the final polishing step is a smaller biomethanation reactor compared to the ex-situ scenario (Scenario 1) that converts the remaining $\mathrm{CO}_{2}$ from the in-situ biomethanation to biomethane.

In the case that wind energy generation is considered and since the plant is located in an on-grid region, in order to deal with the fluctuations in wind electricity generation we assume that the grid serves as storage and thereby a constant power supply to the plant is achieved. The wind farm is dedicated to supply electricity to the electrolysers and by assuming a capacity factor of $30 \%$, the installed capacity of the farm is roughly $28 \mathrm{MW}$ (includes also the electricity opportunity loss). This figure corresponds to approximately 8 state of the art wind turbines.

For continuous operation, the AEL technology was selected due to the significantly lower investment costs (roughly 40\%) [26] while for transient operation PEMEL was chosen as it demonstrates more efficient coupling with dynamic systems [9]. The PEMEL unit is decoupled from the biogas plant via an intermediate hydrogen buffer storage unit that ensures a fixed supply of hydrogen to the digesters is accomplished. The purpose to test the feasibility of dynamic operation is to explore the trade-offs between increased CAPEX (due to increased size of the electrolysers) and reduced OPEX (due to reduced electricity costs). The volume of the storage units was calculated according to Eq.(2).

$\frac{\Delta V_{t}}{t}=z \frac{\left(N_{H 2, \text { in }}-N_{H 2, \text { out }}\right) R T_{\text {storage }}}{P_{\text {storage }}}\left[\mathrm{m}^{3}\right]$

Where $V_{t}$ is the instantaneous volume of the tank, $z$ is the compressibility factor (approximately 1 for hydrogen), $P_{\text {storage }}$ is the pressure in the tank and it is taken equal to the pressure of the PEMEL unit, i.e. 30 bar (should be introduced in $\mathrm{Pa}$ in the equation), $\mathrm{NH}_{2, \text { in }}$ is the inlet molar flowrate of hydrogen (as produced from the electrolyser), $\mathrm{NH}_{2, \text { out }}$ is the outlet hydrogen molar flowrate of the tank (equal for all cases to $67.64 \mathrm{kmol} / \mathrm{h}), \mathrm{R}$ is the gas constant, $8.314 \mathrm{~J} /(\mathrm{mol} \mathrm{K})$, and $\mathrm{T}_{\text {storage }}$ is the average temperature of hydrogen in the tank and it is taken as $60^{\circ} \mathrm{C}$ (should be introduced in $\mathrm{K}$ in the equation). The tank size is the highest value of the $V_{t}$. 


\subsection{Basis for modelling}

Data for the AD process is retrieved from a real waste water plant operating in the UK that processes sewage sludge for biogas production. The features of the AD are presented in Table 3. The sizing of the power to gas components was based on the AD plant and all scenarios were developed in the Matlab/Simulink environment. Two identical digesters, operating in parallel, process sewage sludge with an overall flowrate equal to $593.75 \mathrm{~m}^{3} / \mathrm{d}$. The digesters operate at $39^{\circ} \mathrm{C}$ and atmospheric pressure. The heating for the AD bioreactors is taken as $10 \%$ of the energy content of the biogas [27]. The heat duty of the digesters is then calculated in order to explore heat integration opportunities with the biomethanation reactor and the electrolyser as both of these units release heat. It should be noted here that even if there appears to exist useful heat generated in the biomethanation reactor, recent lab experiments [28][29][30] showcase that, due to heat losses, supply of heat is needed to maintain the temperature of the biomethanation reactor to the desired levels. At larger scale (such as the one investigated herein) because of the surface-to-volume ratio is expected to fall, heat losses are also expected to drop and therefore there may be useful heat generated in the bioreactor. The scope of the present study is to demonstrate the basic material and energy balances of the proposed systems but the reader should be aware of the uncertainty that exists around heat integration opportunities. Further, the process calculations did not consider $\mathrm{H}_{2} \mathrm{~S}$ formation since it is only present at very low concentration, the cost assessment includes a $\mathrm{ZnO}$ adsorption unit that captures $\mathrm{H}_{2} \mathrm{~S}$ [31].

Table 3. Technical data for modelling the AD plant retrieved from an operating waste water treatment plant.

\begin{tabular}{lcc}
\hline Parameter & Value & Unit \\
\hline Reactor volume & 8,000 & $\mathrm{~m}^{3}$ \\
Number of reactors & 2 & - \\
Sludge flowrate & 593.75 & $\mathrm{~m}^{3} / \mathrm{d}$ \\
TDS* content & 10.5 & $\%$ \\
VS** content & 75 & $\%$ (of TDS) \\
Biogas yield & 428 & $\mathrm{~m}^{3} / \mathrm{TDS}$ \\
Biogas composition (dry basis) & $61 / 39$ & $\% \mathrm{CH}_{4} / \mathrm{CO}_{2}$ \\
\hline *TDS refers to total dry solids & & \\
$* *$ VS refers to volatile solids & & \\
\hline
\end{tabular}


Figure 3 is the pseudo-algorithm describing the sequence of the transient operation. The model reads the wholesale electricity prices, Figure 4 [32], and based on the determined threshold prices, it gives a signal to the electrolyser to run either on $5 \%$ or $100 \%$ load. The system response to this load change is in the range of milliseconds [26]. The pairs of the electrolyser size and price thresholds were decided in such a manner in order to maintain an equal annual output for all scenarios. When operating at low capacity, and thus lower voltage, the electrolyser efficiency is greater, i.e. $70 \%$ (LHV basis) or $82.7 \%$ (HHV basis), compared to the full load operation efficiency, i.e. 65\% (LHV basis) or 76.8\% (HHV basis) [26]. It should be also noted that the efficiency of the AEL is typically lower compared to the PEMEL and it was taken as $61 \%$ (LHV basis) or $72.1 \%$ (HHV basis) [26]. Both type of electrolysers operate at $80^{\circ} \mathrm{C}$ while the working pressures are set as 5 and 30 bar for the AEL and PEMEL respectively; for the PEMEL cases, a pressure relief valve is utilised to drop the pressure of hydrogen to the pressure of the biomethanation reactor, i.e. 5 bar. In addition, heat can be recovered from the electrolysers; as depicted in Eq. (3) and (4), the amount of recoverable heat, $Q$, equals the fraction, $\eta_{\Delta H}$, of electrical work, $W$, not converted into enthalpy change, $\Delta H_{R}^{o}$, in the water splitting reaction [33].

$\eta_{\Delta H}=\frac{\Delta H_{R}^{o}}{W}[-]$

$Q=W\left(1-\eta_{\Delta H}\right)\left[\frac{J}{m o l}\right)$

The consumption of the deionised water in the electrolysers is taken as $10 \mathrm{~L}$ of water per $\mathrm{kg}$ of $\mathrm{H}_{2}$ produced [34]. 


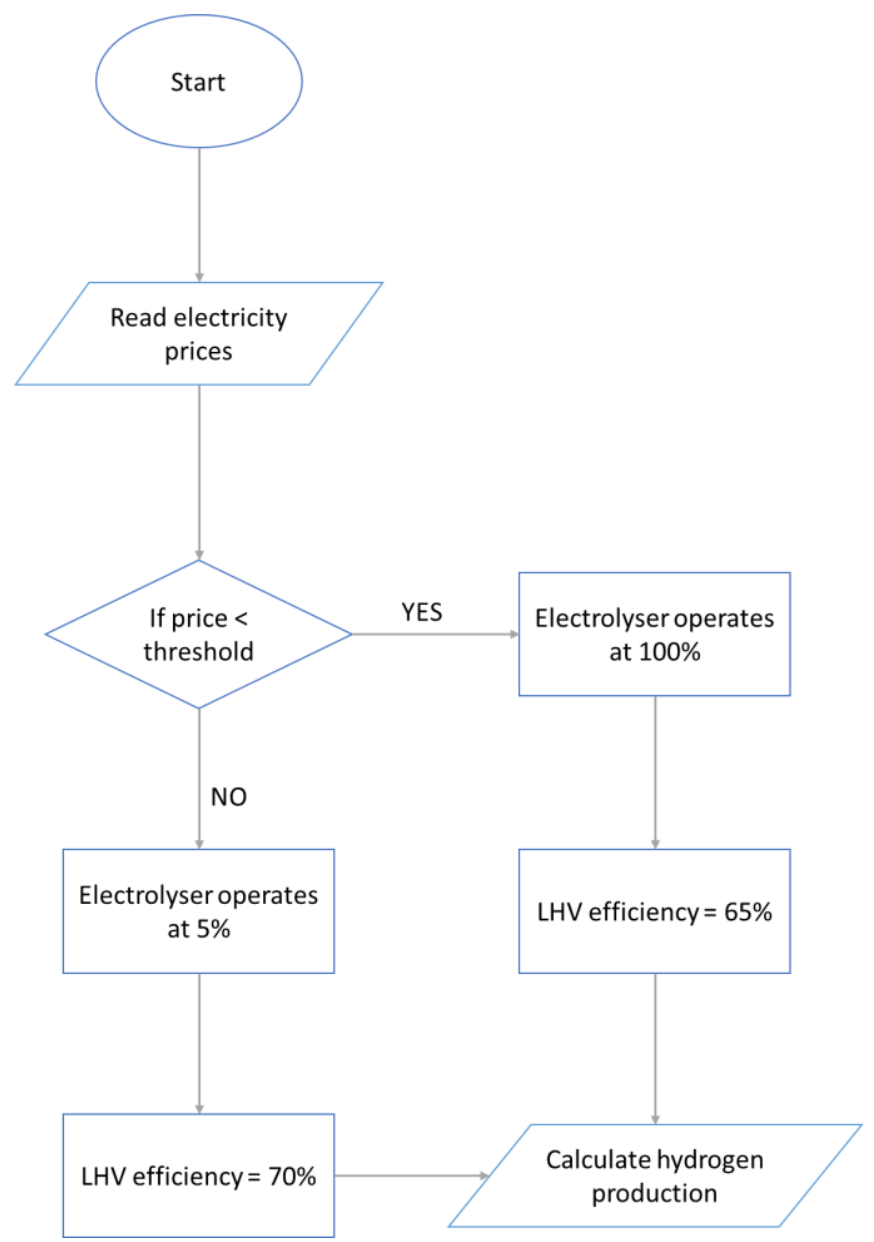

Figure 3. Pseudo-algorithm presenting the methodology for the scenarios in transient operation.

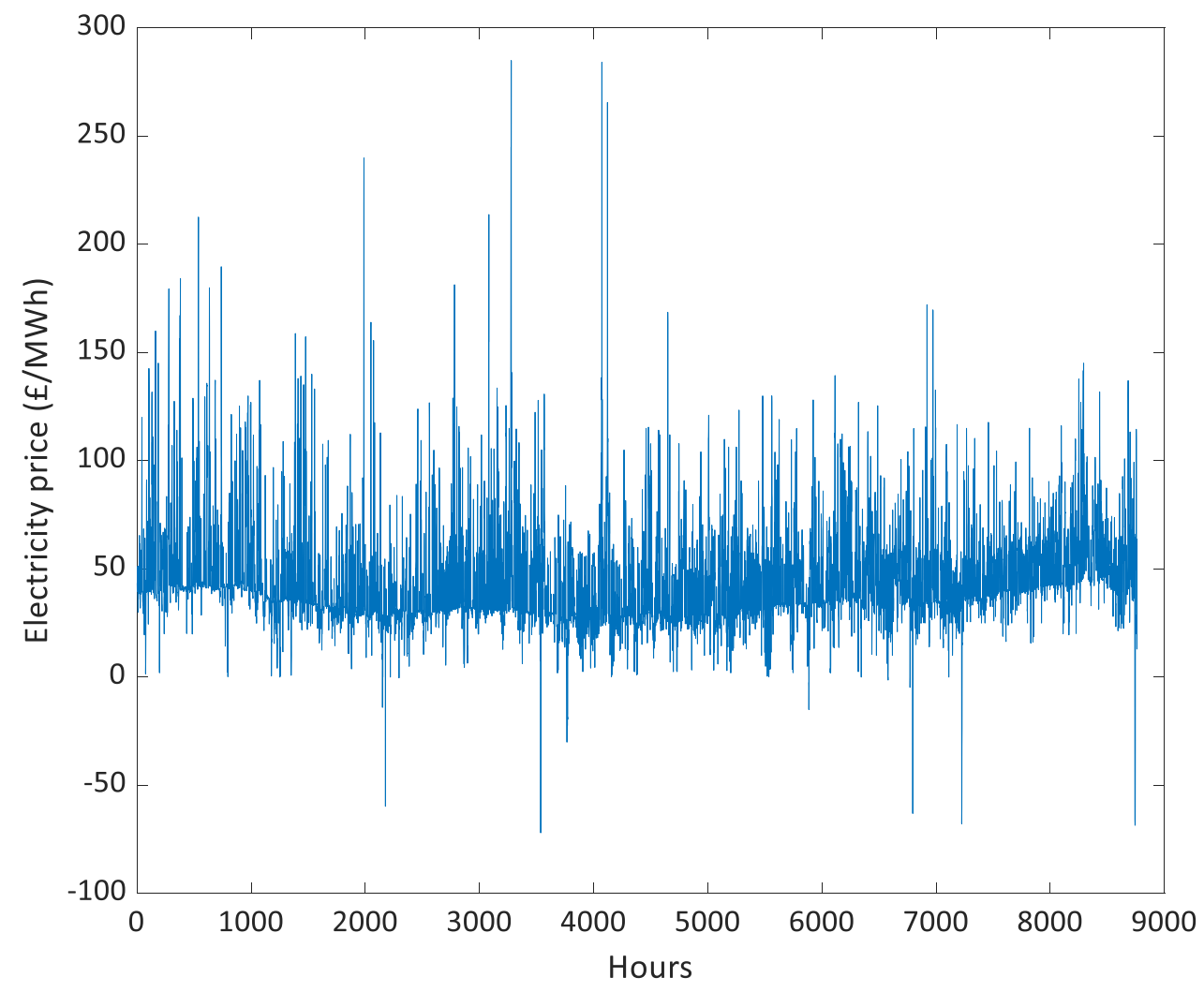

Figure 4. Wholesale electricity prices in the UK in 2017 [32]. 
Regarding the biomethanation reactor, in all cases the $\mathrm{H}_{2}: \mathrm{CO}_{2}$ feed ratio is 4 and the electrical parasitic demand is equal to $0.16 \mathrm{kWh} / \mathrm{Nm}^{3}$ of input gas flow [35]. As mentioned before, heat is released during biomethanation and heat integration opportunities are discussed in the section 3.1. The ex-situ biomethanation operates at mesophilic conditions of $60^{\circ} \mathrm{C}$ and pressure of 5 bar [36] and the conversion of $\mathrm{CO}_{2}$ to methane is taken as $98.6 \%$ [11]. For the in-situ biomethanation, the hydrogen produced by the electrolyser is split into two streams. One stream is sent to the digesters and its flowrate is adjusted so that the final composition of the biogas to be $90 \%$ methane (full hydrogen conversion is assumed). In all cases, the final biomethane stream (both sludge and electrolysis derived) contains more than $99 \%$ of methane on volume basis. The required volumetric mass transfer coefficient (kLa) in the digesters is calculated to assess whether gas-liquid mass transfer could be rate limiting in this stage. The second stream is fed to the biomethanation reactor.

\subsection{Basis for economic evaluation}

An economic model has been developed that calculates the levelised cost of energy (LCOE), Eq.(5). In the LCOE equation, CAPEX is the cost at year 0 while OPEX are the costs from year 1 to year 20. A discount rate of $10 \%$ is selected as a legitimate figure that can capture the effects of risk. The plant is located in the UK and prices and costs are presented in GBP2017. The lifetime for all scenarios is 20 years while the plant operates $8760 \mathrm{~h} / \mathrm{y}$.

As depicted in Eq.(5), the LCOE necessitates the calculation of CAPEX and OPEX. The overall CAPEX is estimated as a multiple of the bare equipment cost and the methodology is presented in Table 4 [37][38][39]. The indirect costs for in-situ biomethanation should be expected to be higher than the ex-situ as the in-situ is a lower TRL technology and thereby it comes with increased engineering costs and contingencies. The scaling factor correlation, as shown in Eq. (6) has been used to calculate the equipment cost; data is presented in Appendix A Table A.1 [20] [40] [41] [42] [43] [44]. Lastly, any salvage value is assumed to be fully offset by decommissioning costs.

$L C O E(£ / M W h)=\frac{\sum_{n=0}^{20} \frac{\text { costsin year } n}{(1+\text { discount rate })^{n}}}{\sum_{n=1}^{20} \frac{\text { MWhof methane produced in year } n}{(1+\text { discount rate })^{n}}}$

$C=C_{0}\left(\frac{S}{S_{0}}\right)^{f}$

Where

$C=$ actual cost

$C_{0}=$ base cost

$S=$ actual capacity

$S_{0}=$ base capacity

$f=$ scaling factor 
Table 4. CAPEX estimation methodology [37][38][39].

\begin{tabular}{ll}
\hline Cost component & Factor \\
\hline Direct costs (DC) & \\
Purchased equipment cost (PEC) & $100 \%$ PEC \\
Purchased equipment installation & $39 \%$ PEC \\
Instrumentation and controls & $26 \%$ PEC \\
Piping & $31 \%$ PEC \\
Electrical systems & $10 \%$ PEC \\
Indirect costs (IC) & $21.9 \% / 30 \%$ DC \\
Fixed Capital Investment (FCI) & DC+IC \\
Start-up costs (SUC) & $5 \% \mathrm{FCl}$ \\
Interest during construction (IDC) & Computed \\
CAPEX & FCI + SUC + IDC \\
$* *$ Working Capital (WC) & $5 \% \mathrm{FCl}$ \\
\hline *Low value refers to the ex-situ scenarios/ high value refers to in-situ scenarios \\
$* *$ Working capital is applied in the year before operation and recovered at the end \\
of the plant life and hence it is not depreciated \\
\hline
\end{tabular}

OPEX is the sum of the fixed operations and maintenance costs (FOM) (see Appendix A Table A.2 [43][45][46][47]) and variable costs (VC) that comprise electricity and other utilities cost. As mentioned before, an opportunity loss (OppLoss) related to the loss of the biogas derived electricity is also included in the OPEX. The total amount of the required labour hours has been estimated based on best practice functions associated with highly automated fluid processing plants according to the work carried out by Peters et al. [46] as follows, Eq.(7):

$h_{\text {labor }}\left[\frac{h}{\text { year }}\right]=2.13 \times$ plant capacity $\left[\frac{k_{\text {fuel_output }}}{h}\right]^{0.242} \times n_{\text {process_steps }} \times \frac{h_{\text {plant_operation }}}{24}$

The plant capacity is stated by means of the product output, i.e. biomethane in the current work, the number of process steps, $n_{\text {process_steps, }}$ corresponds to the sections (one or more unit operations) within the production line in which substantial chemical composition and/or thermodynamic change occurs and $h_{\text {plant_operation }}$ are the annual operating hours. The hourly labour cost has been taken as $15 \mathrm{f} / \mathrm{h}$ [48].

The VC include electricity costs and the costs for deionised water and cooling water. For the grid electricity price a fee of $57.6 \mathrm{f} / \mathrm{MWh}$, which accounts for grid costs, levies and taxes, is applied to the wholesale electricity price for the grid connected scenarios. This fee is the difference between the average retail price of electricity (=102.4 $\mathrm{f} / \mathrm{MWh}[49])$ for industrial very large size consumers and the average wholesale electricity price in 2017 (=44.8 f/MWh [32]). Therefore, for the transient mode cases the electricity cost is calculated on an hourly basis as the sum of the hourly wholesale electricity price and the fee. In addition, The cost of the deionised water (supplied to the electrolysers) is taken 
as $10 \mathrm{f} / \mathrm{t}$ [43] while the cooling water as $0.025 \mathrm{f} / \mathrm{t}$ [46]. Finally, for the scenarios that are powered by renewable electricity the electricity price is taken as the LCOE of on-shore wind generation (to account for generation costs), i.e. $65 \mathrm{f} / \mathrm{MWh}$ [50], plus a fee for transmission network costs equal to 24.5 £/MWh [51].

The examined P2G infrastructures generate as by-product oxygen that has a market value because of its demand in the steel and chemical industries and thereby revenues can be generated; a market price of $70 \mathrm{f} /$ tonne of $\mathrm{O}_{2}[52]$ is assumed herein. In addition, the projects can receive payments from the electricity system operator for offering grid balancing services. PEMEL and AEL have demonstrated similar performances in frequency-regulation experiments carried out at the National Renewable Energy Laboratory (NREL) [53]. Nevertheless, in the present study only the scenarios that include PEMEL (Scenarios 3-5) are qualified for this scheme as they consume grid derived electricity. The grid balancing fee is taken as a 13.2 $\mathrm{f} / \mathrm{MWe}$ (installed electrolyser capacity) and it is paid on a yearly basis [54]. Finally, the examined plant is eligible to receive the renewable heat incentive (RHI), a fee that targets to decarbonise the heating sector in the UK; a fee of $62 \mathrm{f} / \mathrm{MWh}$ is paid to the plant. The RHI can be received for the sludge derived biomethane while a carbon footprint assessment is necessary to test if the electrolytic hydrogen is also eligible for the RHI. It should be noted that the main reason for a WWTP to repurpose its production line and target biomethane production instead of electricity is the RHI.

\subsection{Basis for lifecycle carbon footprint assessment (CFA)}

The examined plant is eligible to receive RHI payments for the sludge derived biomethane and in order to identify if the electrolytic biomethane meets the RHI requirements a carbon footprint assessment (CFA) for each scenario has been carried out; the system boundaries for the CFA are depicted in Figure 5. The current UK regulations require that the biomethane must have lifecycle greenhouse gas emissions of less than or equal to 34.8 grams of carbon dioxide equivalent per MJ of biomethane (measured as the low heating value) [55]. If the carbon footprint (CF) of the electrolytic biomethane is below this threshold, then the project is assumed to be eligible for $\mathrm{RHI}$ payments for the whole amount of biomethane produced; in the case that the CF of the electrolytic biomethane is above the threshold then the project receives RHI only for the sludge derived biomethane.

The main input stream to the CFA is the electricity. The electricity stream comprises the consumption of the electrolyser, utilities and imports due to opportunity loss. Additional contributions (signified herein as 'others') such as construction and raw materials are responsible for approximately 0.1-0.2 $\mathrm{kgCO}_{2}$,eq/ $\mathrm{Nm}^{3}$ of methane [56]. The UK electricity mix emits approximately $97.7 \mathrm{gCO}_{2}$,eq /MJ [57] while a value of $3 \mathrm{gCO}_{2}$,eq /MJ [50] has been considered for the emission intensity (EI) of on-shore 
wind energy generation. The functional unit (FU) is $1 \mathrm{MJ}$ of electrolytic biomethane produced on a LHV basis. In addition, oxygen is obtained as by-product and we assume that this replaces oxygen produced from a conventional air separation unit ASU; the energy (electrical) requirement for cryogenic air separation is $0.4 \mathrm{MJ} / \mathrm{kgO}_{2}$ [58]. Then, Eq. (8) has been utilised to calculate the $\mathrm{CF}$ of the electrolytic methane for each case.

$C F_{\text {electolytic-biomethane }}=C F$ of electricity $+C F$ of others $^{\prime}-$ Credits from $\mathrm{O}_{2}$

\section{System boundaries for the CFA}

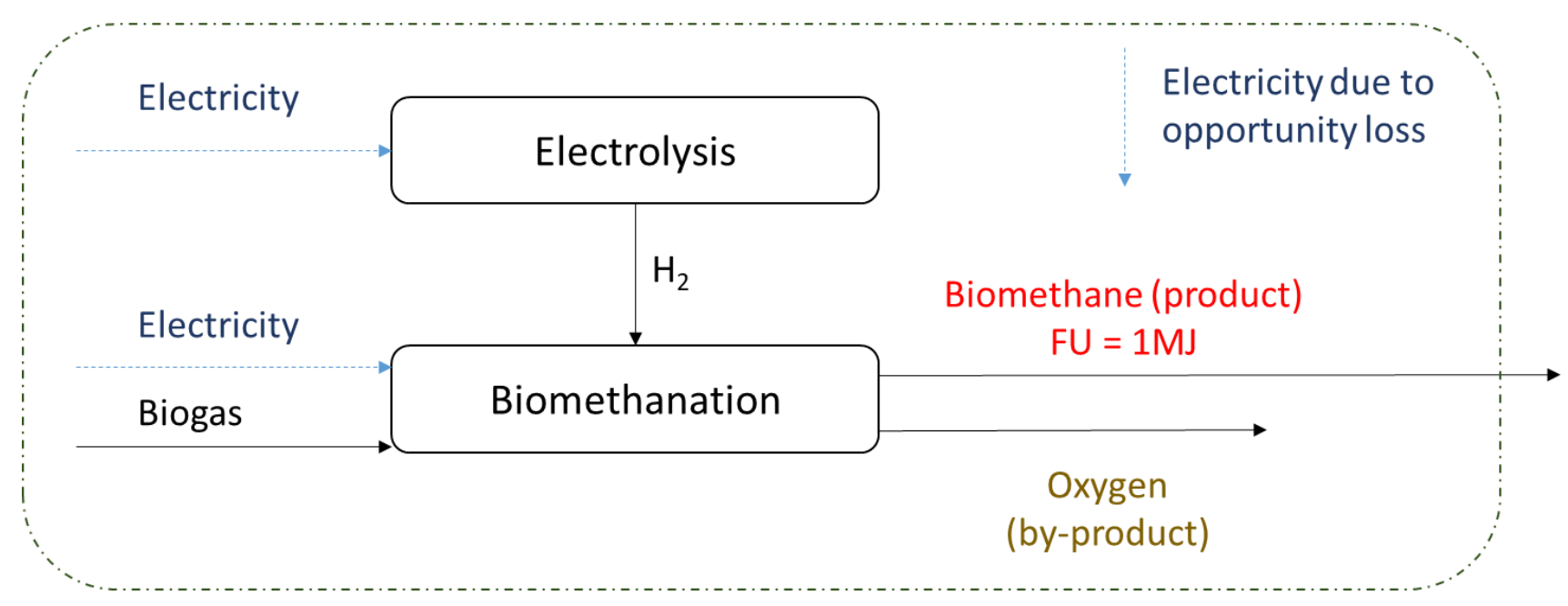

Figure 5. Framework of the carbon footprint assessment.

\section{Results and discussion}

\subsection{Mass and Energy balances}

Figure 6 is a visual representation of the basic M\&E balances. Sewage sludge of $217,000 \mathrm{~m}^{3} / \mathrm{y}$ is treated and the final biomethane yield is identical for all the cases and equal to $10.60 \mathrm{MW}$; 6.5 is the sludge derived biomethane and 4.1 is the electrolytic biomethane. For the in-situ cases, the amount of hydrogen that is sent to the digesters is configured in such a manner that the methane content in the biogas to be $90 \%$ (full conversion of hydrogen is assumed), equal to $896 \mathrm{t} / \mathrm{y}$ or on average of $102 \mathrm{~kg} / \mathrm{h}$. Under these conditions the required kLa of combined digesters, for non-limiting gas-liquid mass transfer, was approximately $8.3 \mathrm{hr}^{-1}$ or $0.0023 \mathrm{~s}^{-1}$ which was considered to be well within reach of a retrofitted gas injection system and several orders of magnitude below those of industrial bioreactors. For all the cases, the amount of heat released is more than enough to cover the heat duty of the digesters. The biomethanation reactor in the Scenario 1 releases more heat but consumes more electrical energy as the size of the reactor in this case is greater than the other scenarios. The Scenarios 3, 4 and 5 release less heat from the electrolysers compared to the Scenario 1 and Scenario 2 but this only signifies that the electrical efficiency of the PEMEL is greater than the AEL. In addition, even if the 
size of the electrolysers in the PEMEL cases is different the amount of energy produced is the same due to the dissimilar operating hours at full and low load. Also, the required volume for the buffer hydrogen storage increases with increasing electrolyser size as larger flows of hydrogen have to be buffered. Table 5 depicts the main operating features of the transient mode cases. It should be noted here that the balance of the material flows around the biomethanation reactor is the water produced as per the Sabatier reaction. This water is recycled to the WWTP plant. Finally, as depicted in the Figure 7, the main contributor to the electricity consumption for all cases is the electrolyser accounting for roughly $73 \%$. Finally, the share of the additional electricity needed due to the biogas opportunity loss is noticeable and in the range of $23 \%$ to $25 \%$ for all the scenarios.

\section{Scenario 1}

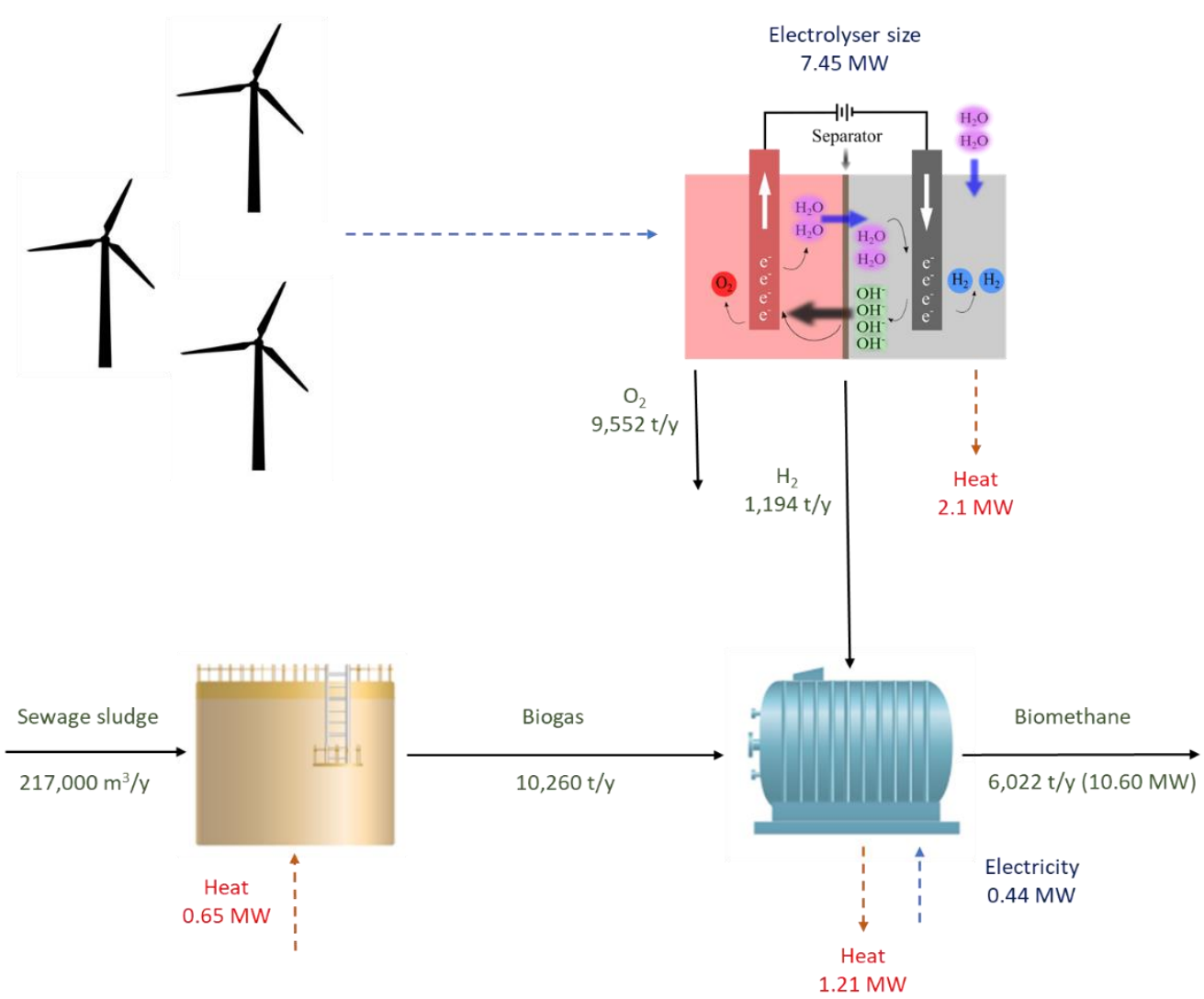


Scenario 2
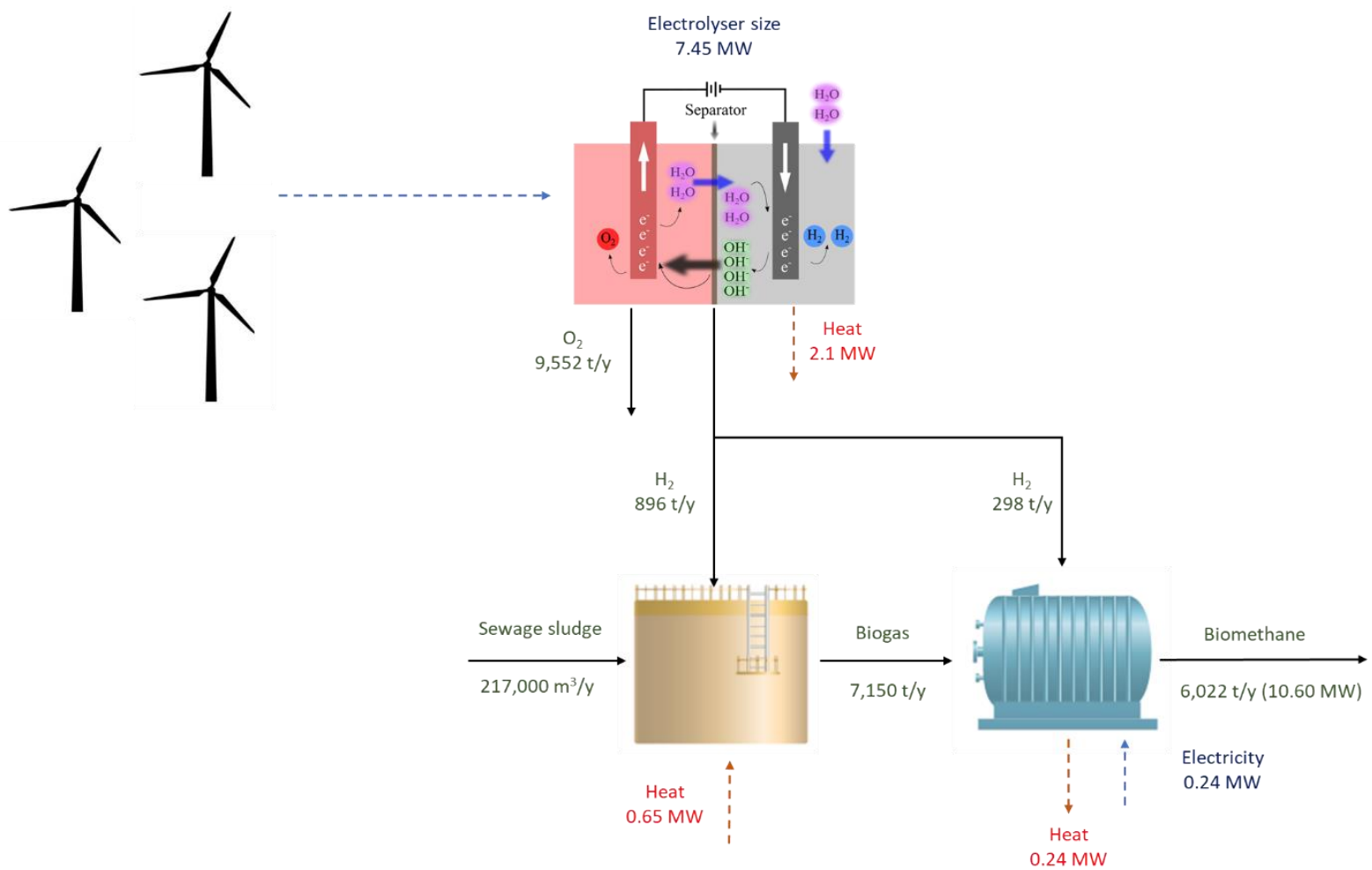

Scenario 3

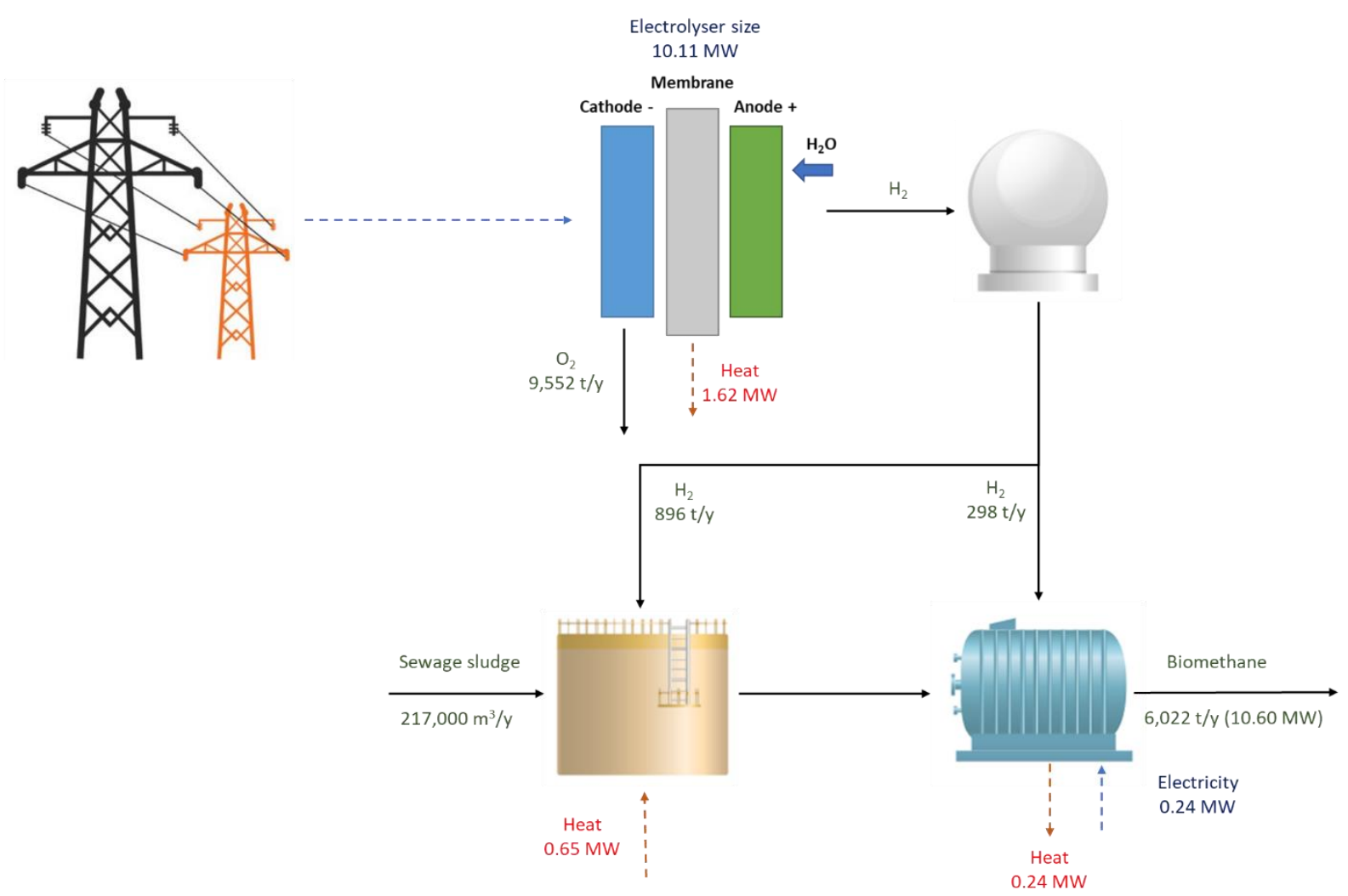



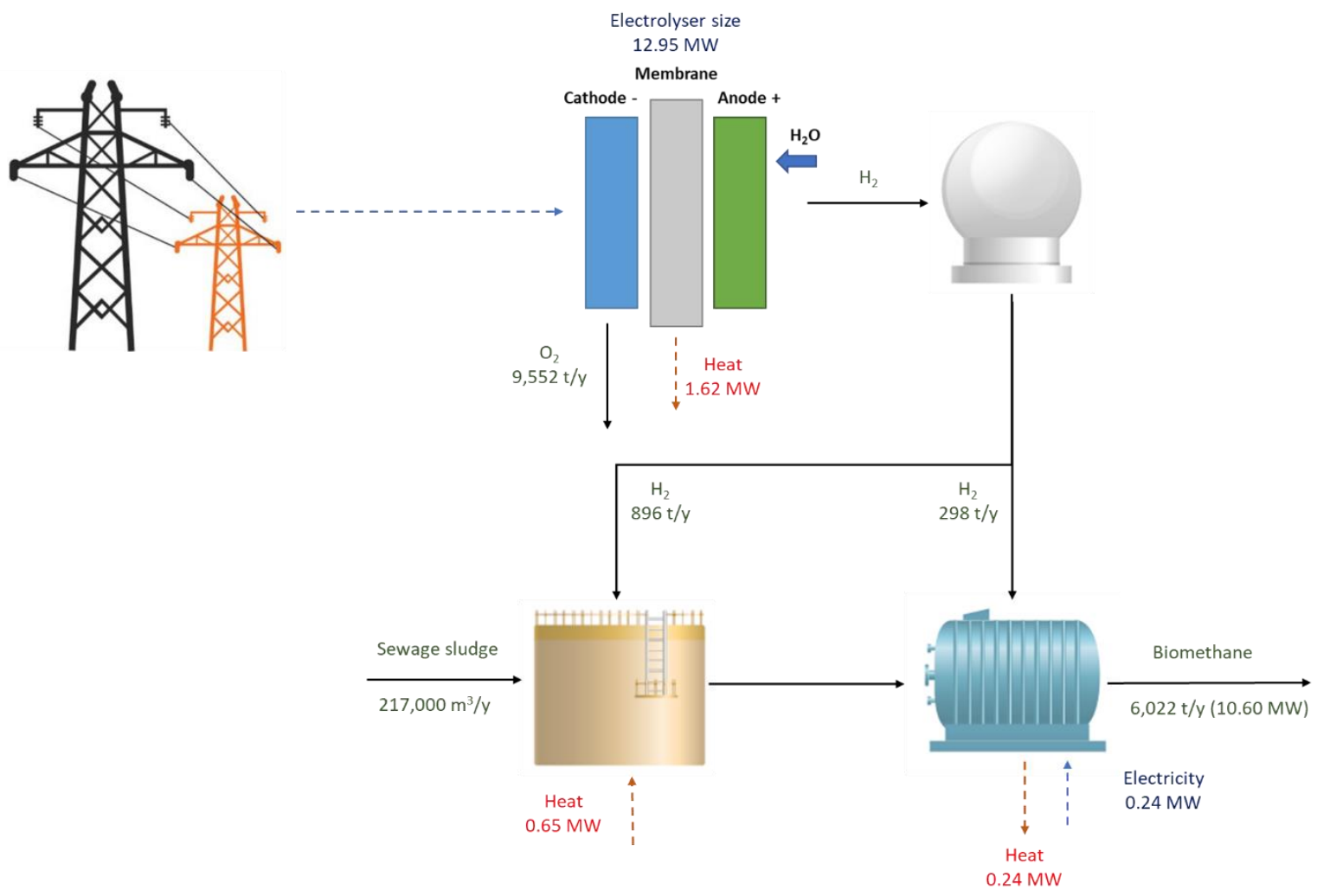

Scenario 5

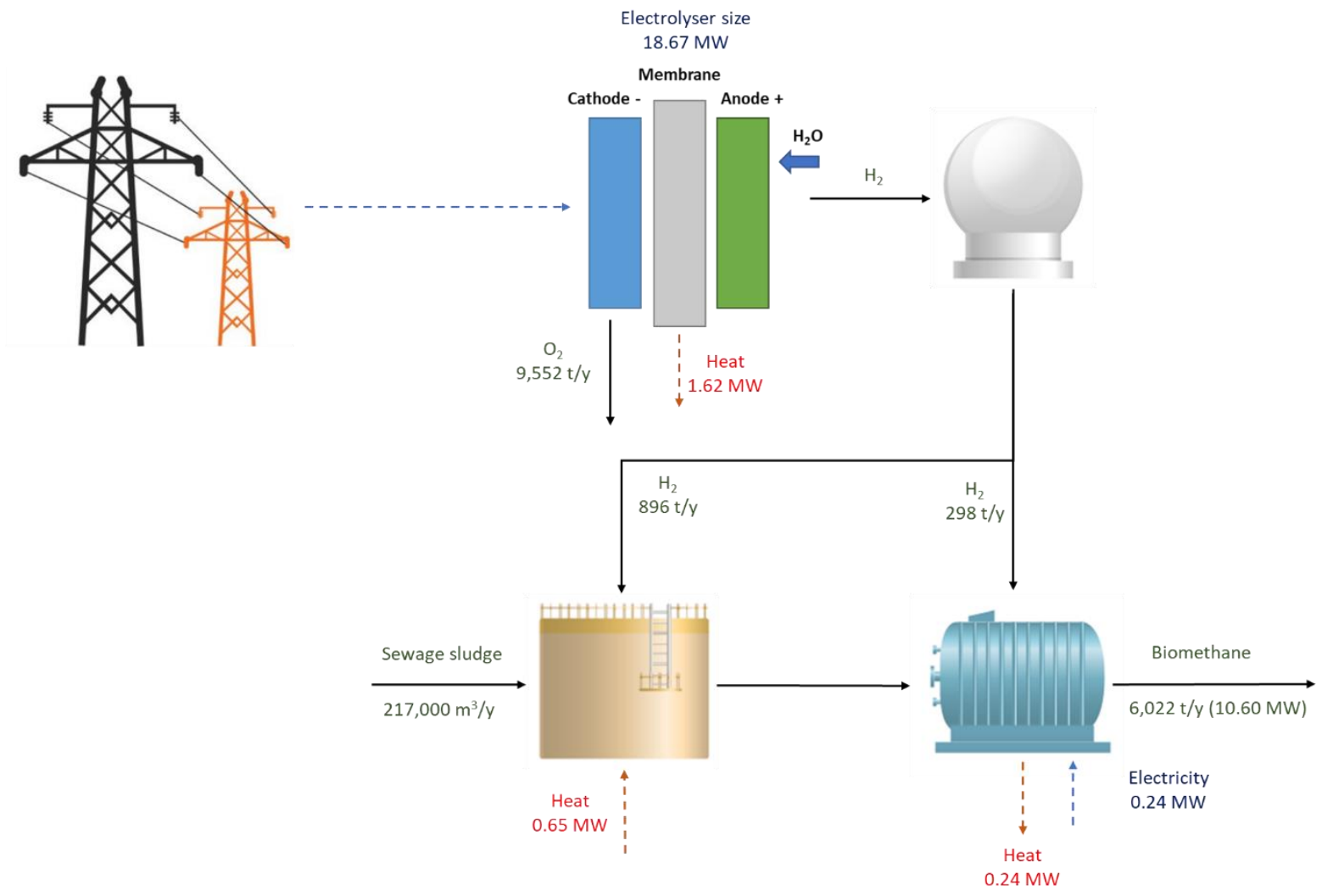

Figure 6. Schematic of the basic mass and energy balances for the examined scenarios 
Table 5. Operating specifications of the transient mode scenarios

\begin{tabular}{lccc}
\hline & Scenario 3 & Scenario 4 & Scenario 5 \\
\hline Electrolyser size (MW) & 10.11 & 12.95 & 18.67 \\
Full load hours $(\mathrm{h})$ & 5,922 & 4,522 & 2,995 \\
Low load hours $(\mathrm{h})$ & 2,838 & 4,238 & 5,765 \\
Electrolyser stack energy consumption (MWh/y) & 61,320 & 61,320 & 61,320 \\
Heat released in the electrolyser (MWh/y) & 14,226 & 14,226 & 14,226 \\
Volume of the hydrogen buffer storage $\left(\mathrm{m}^{3}\right)$ & 42 & 45 & 50 \\
\hline
\end{tabular}

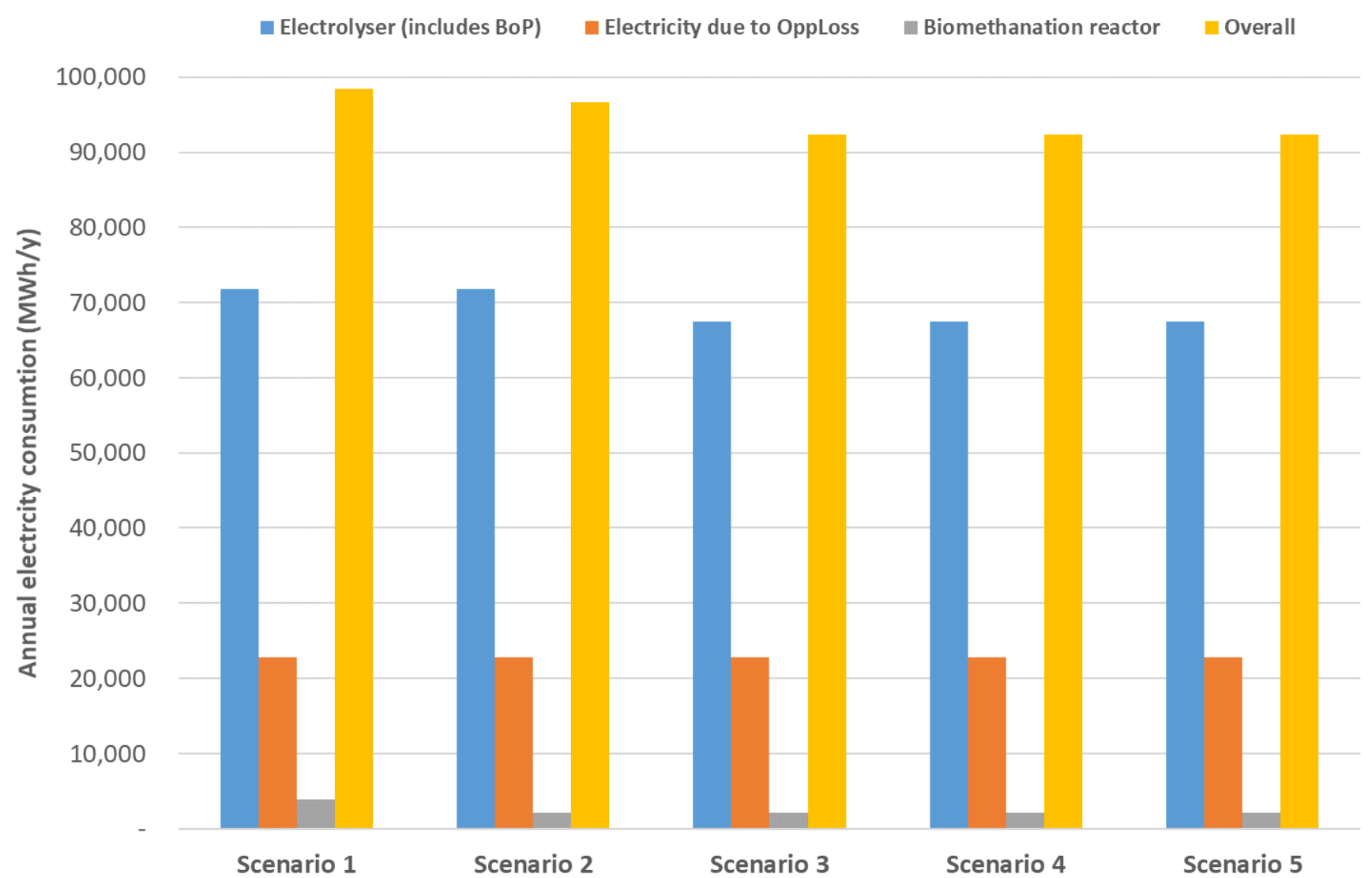

Figure 7. Breakdown of the electricity consumption for each scenario.

\subsection{Economic assessment}

Figures 8 and 9 provide the detailed itemisation of the purchased equipment cost and OPEX respectively for each scenario. In all the cases, the cost of the electrolyser dominates the equipment costs, i.e. $64 \%, 81 \%, 90 \%, 92 \%$ and $94 \%$ for the Scenarios 1, 2, 3, 4 and 5 respectively. For the Scenario 1 , the share of the biomethanation reactor due to increased size is higher than the other cases and equal to $35 \%$. 
Similar to most power to gas projects the electricity price is the chief OPEX contributor. All scenarios have similar OPEX with the cases operating in dynamic mode to attain slightly lower electricity costs but the increased FOM offset this difference. In addition, the benefit of operating the electrolyser when the electricity is cheap (Scenarios 3, 4 and 5) is not apparent as the electricity cost is not sufficiently low when additional costs (levies, taxes, grid costs etc.) are considered.

As shown in Figure 10, the LCOE for all projects is more than 8 times greater than the natural gas price, i.e. $15 \mathrm{f} / \mathrm{MWh}$. Therefore, it is clear that significant incentives are required for the commercialisation of the examined power to gas scenarios and the effect of policy schemes is investigated in the Section 3.4. Table 6 summarises the basic economic results for each case and it can be extracted from the normalised outcomes that all scenarios are OPEX intensive. Consequently, the procurement of cheap electricity either in the form of tax exemptions or as a result of technological advances should be prioritised. In addition, the effect of the CAPEX is greater in the Scenarios 3-5 due to the increased size of the electrolysers and the higher cost of the PEMEL compared to the AEL.

16

$$
\text { Injection system }
$$
5.20

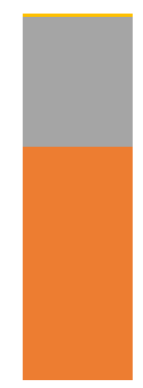

Scenario 1

4.08

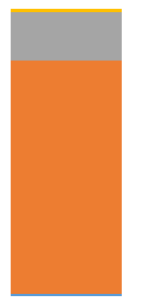

Scenario 2
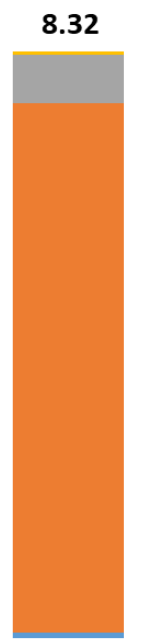

Scenario 3
10.09

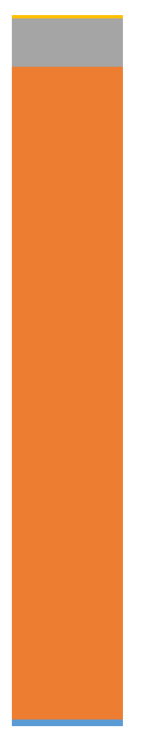

Scenario 4

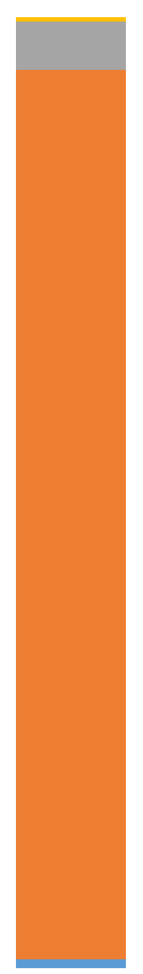

Scenario 5

Figure 8. Breakdown of the purchased equipment cost for each scenario. 


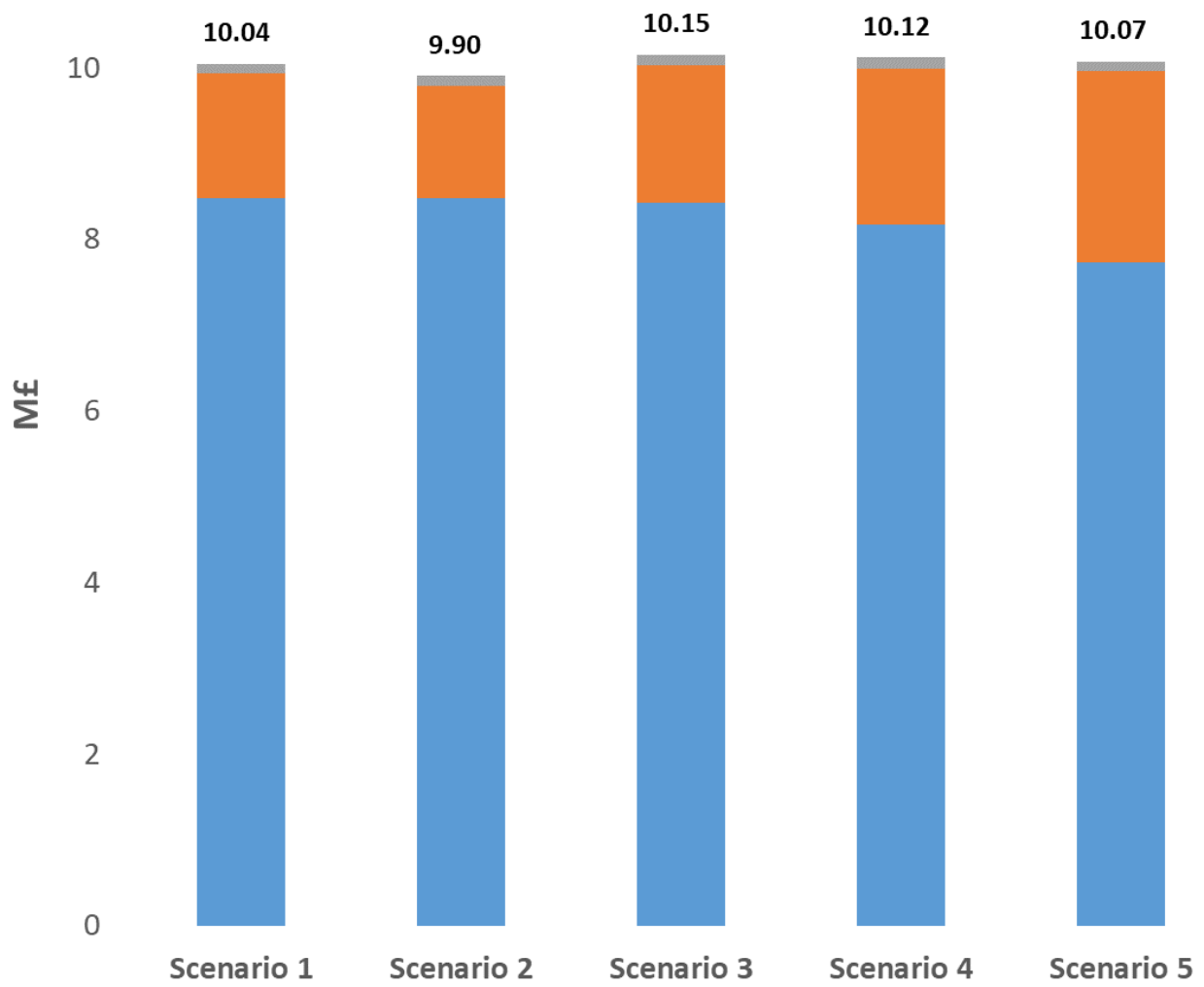

Figure 9. Breakdown of the OPEX for each scenario. FOM is the fixed opeartions and maintenance cost and VC the variable costs.

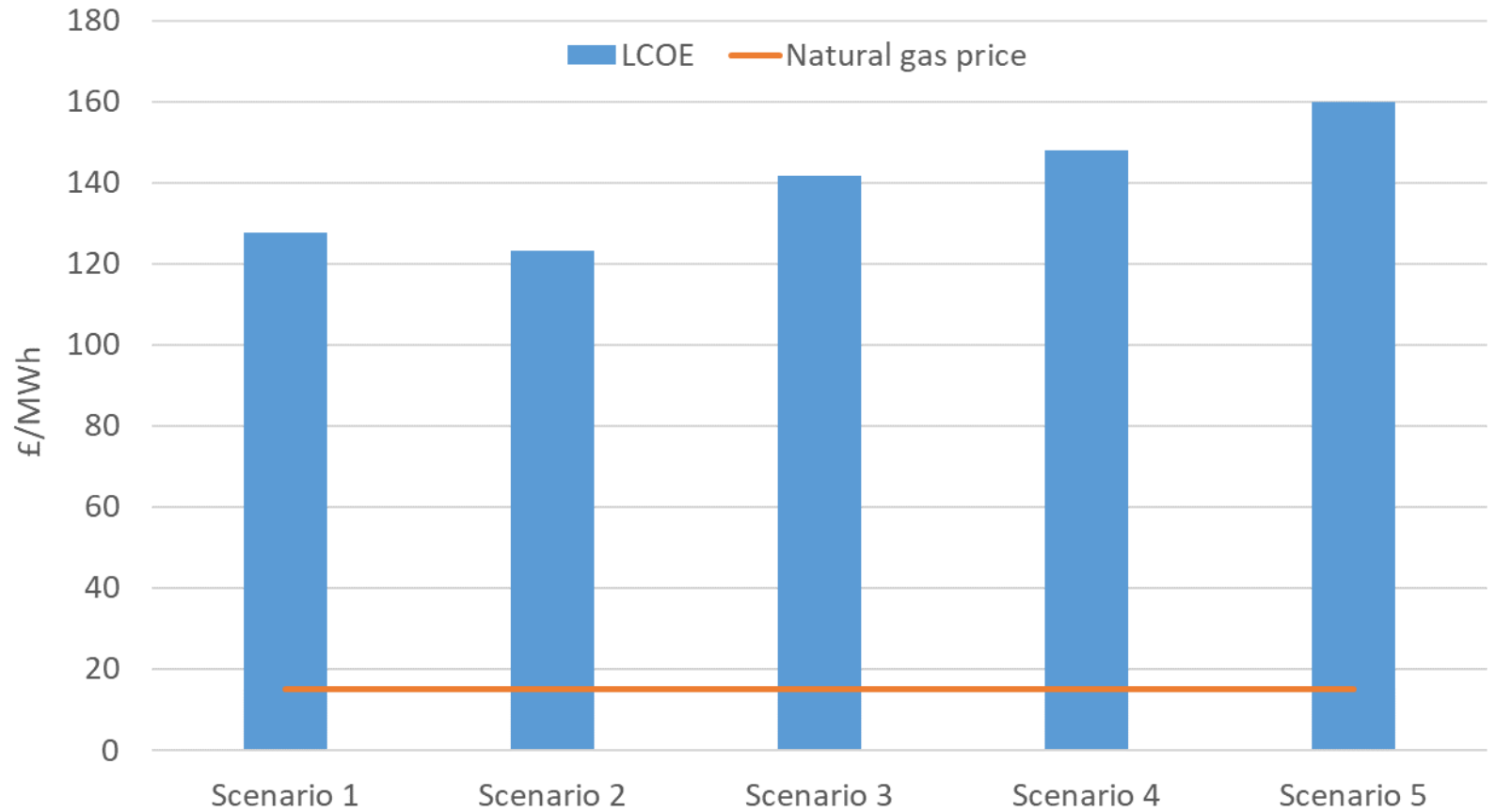

Figure 10. The LCOE for each scenario. The natural gas price (=15 f/MWh) is presented for comparisons. 
Table 6. Summary of the economic results for each scenario.

\begin{tabular}{lccccc}
\hline & Scenario 1 & Scenario 2 & Scenario 3 & Scenario 4 & Scenario 5 \\
\hline CAPEX (Mf) & 13.99 & 11.70 & 23.87 & 28.93 & 38.67 \\
OPEX (Mf/y) & 10.04 & 9.90 & 10.15 & 10.12 & 10.07 \\
Normalised CAPEX (f/MWh) & 18 & 15 & 30.6 & 37.2 & 49.7 \\
Normalised OPEX (f/MWh) & 109.8 & 108.3 & 111 & 110.7 & 110.1 \\
LCOE (f/MWh) & 127.8 & 123.3 & 141.6 & 147.9 & 159.8 \\
\hline
\end{tabular}

\subsection{Carbon footprint assessment}

Table 7 presents the results of the carbon footprint assessment. It can be seen that only for the Scenarios 1 and 2 the $\mathrm{CF}$ of the electrolytic biomethane is below the $\mathrm{RHI}$ threshold of $34.8 \mathrm{gCO}_{2}$,eq /MJ. Hence, Scenarios 1 and 2 receive RHI for the whole amount of the biomethane produced, i.e. 10.6 MW, while the Scenarios 3, 4 and 5 receive $\mathrm{RHI}$ only for the sludge derived biomethane, i.e. 6.5MW. In the Scenarios 3-5 the decisive factor of the overall emissions is the grid electricity imports mainly to power the electrolyser. The energy mix of the UK grid, as it is at the moment, appears not to be suitable for power to gas applications and on-site renewable electricity generation appears to be a prerequisite for sustainability. In order for the Scenarios 3-5 to be eligible for the RHI, the emission intensity of the grid should experience a dramatic fall of approximately $88 \%$ or equally down to 11.7 $\mathrm{gCO}_{2}$,eq / $\mathrm{MJ}$ of generated electricity. According to recent projections, such a drop to the grid emission intensity can be achieved in 2035 when the projected value is $11.4 \mathrm{gCO}_{2}$,eq /MJ [59].

Table 7. Results of the carbon footprint assessment for each case. The functional unit $1 \mathrm{MJ}$ of electrolytic methane injected to the grid.

\begin{tabular}{lccccc}
\hline & Scenario 1 & Scenario 2 & Scenario 3 & Scenario 4 & Scenario 5 \\
\hline CF electricity $\left(\mathrm{gCO}_{2}, \mathrm{eq} / \mathrm{MJ}\right)$ & 8.22 & 8.07 & 251.16 & 251.16 & 251.16 \\
$\mathrm{CF}$ others $\left(\mathrm{gCO}_{2}\right.$,eq /MJ) & 6.09 & 4.26 & 5.05 & 5.17 & 5.32 \\
Credit from $\mathrm{O}_{2}\left(\mathrm{gCO}_{2}, \mathrm{eq} / \mathrm{MJ}\right)$ & -2.86 & -2.86 & -2.86 & -2.86 & -2.86 \\
$\mathrm{CF}_{\text {electrolytic-biomethane }}\left(\mathrm{gCO}_{2}\right.$,eq $\left./ \mathrm{MJ}\right)$ & 11.45 & 9.47 & 253.35 & 253.47 & 253.62 \\
\hline
\end{tabular}

\subsection{Effect of policy schemes and oxygen revenues}

Figure 11 depicts the cumulative effect of the RHI, the revenues of selling oxygen and the grid balancing services. In addition, as most of the ventures that are associated with the implementation of renewable energy systems (or systems that have the potential to be renewable in the near future) 
seek or enjoy tax exemptions, we investigated the effect of an optimistic scenario in which electricity is delivered free of any taxes, levies and charges. Finally, the effect of implementing a carbon price is also assessed herein. Presently, the UK takes part in the European Emissions Trading System (EU-ETS) while future deliberations suggest the formation of a UK-ETS or the application of a carbon tax [60]. The implementation of the $\mathrm{CO}_{2}$ price increases the market price of the fossil natural gas and consequently the biomethane can be sold at a higher price. A carbon price equal to the current EUETS carbon price, i.e. $20 \mathrm{f} /$ tonne of $\mathrm{CO}_{2}$ [61] is assumed herein. The emission factor for the NG is taken as $0.2 \mathrm{tCO}_{2} / \mathrm{MWh}$ (HHV basis)[57] and thereby the market price of the NG rises to $19 \mathrm{f} / \mathrm{MWh}$.

The implementation of the considered policy schemes and oxygen revenues causes a drop in the LCOE for all scenarios that lies in the range of $57 \%$ to $75 \%$. The largest fall is observed in the Scenarios 1 and 2 as the effect of the RHI is greater compared to the other cases since both the sludge and the electrolytic biomethane is eligible for payments. Even in this optimistic policy environment, all cases require more support to compete with natural gas, i.e. 16.9, 12.4, 27.2, 33.9 and $49.1 \mathrm{f} / \mathrm{MWh}$ for the Scenarios 1, 2, 3, 4 and 5 respectively. Therefore, it is clear then that additional economic incentives are necessary or technical enhancements have to be realised to improve the competitiveness of the examined projects.

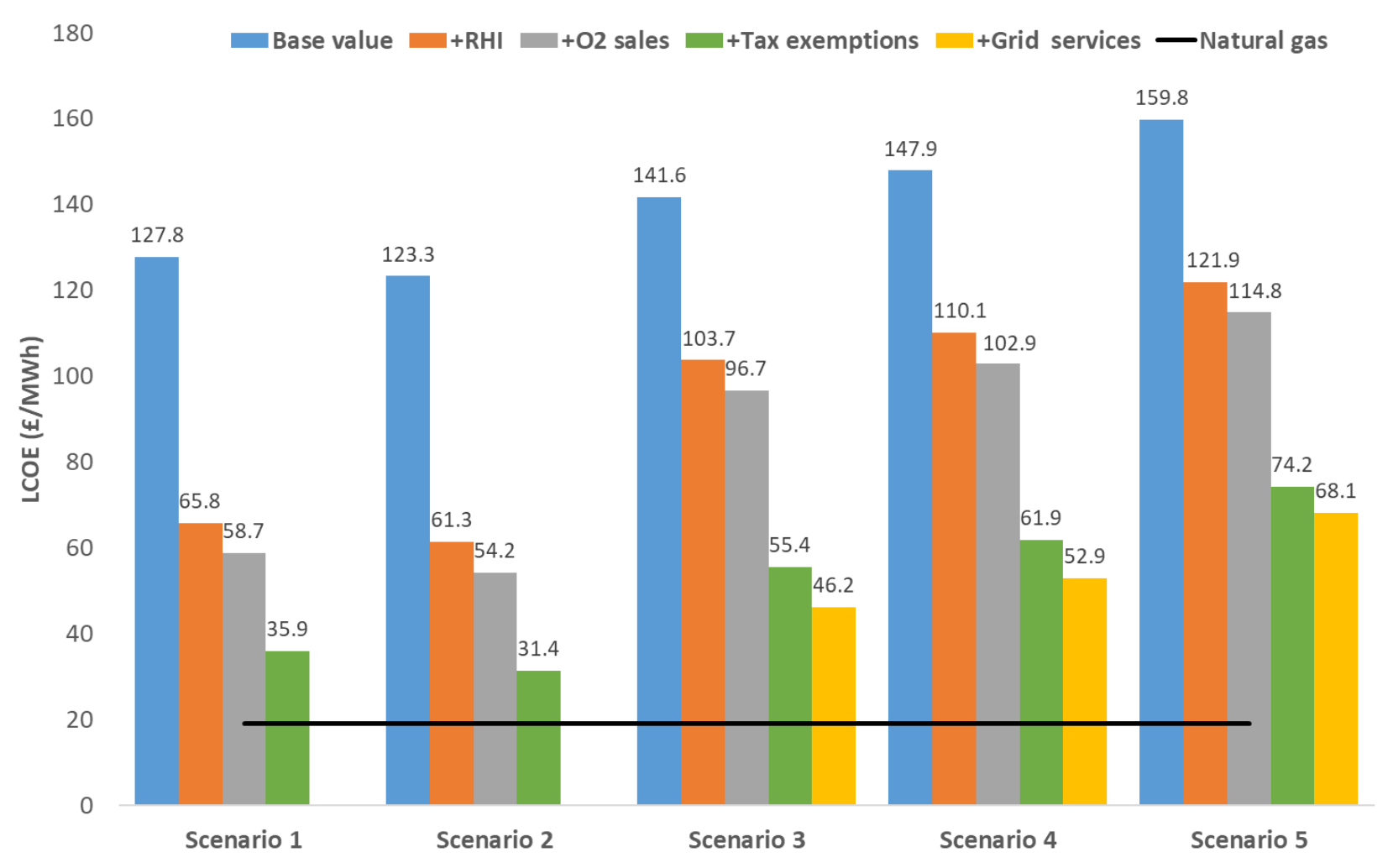

Figure 11. Cumulative effect of various policy schemes and $\mathrm{O}_{2}$ sale credits on the LCOE for each scenario. The NG price, for a carbon price of $20 \mathrm{f} / \mathrm{t} \mathrm{CO}_{2}$, is $19 \mathrm{f} / \mathrm{MWh}$ and is illustrated for comparisons. 


\subsection{Sensitivity analysis}

The influence of several techno-economic parameters on the LCOE of each case has been evaluated to identify sensitivities and favourable conditions. The economic assessment revealed as the major bottleneck for all cases the production of hydrogen. As a result, the equipment cost of the electrolyser, the electrolyser efficiency and the electricity price have been varied to quantify their effect. The purchased equipment cost $(\mathrm{PEC})$ of the electrolysers, both AEL and PEMEL, is projected to be halved in the near future due to mass production and technical advances such as optimisation of operational window and utilisation of improved materials [26][62]. In addition, a similar optimistic trend is expected for the efficiency of the electrolyser whereby increases in efficiencies of up to $10 \%$ (relative increase) are projected even if improving the efficiency of the electrolysers is not expected to be substantial [26]. The effect of the electricity price was also examined by varying the nominal value by $\pm 20 \%$. The variation of the electricity price includes only generation costs; the additional taxes and grid costs are added as a fixed cost assuming the same values presented in the Section 2.3. Finally, the effect of the discount rate and the project lifetime have been also evaluated. It should be noted that the LCOE includes RHI payments, oxygen revenues and grid service fees.

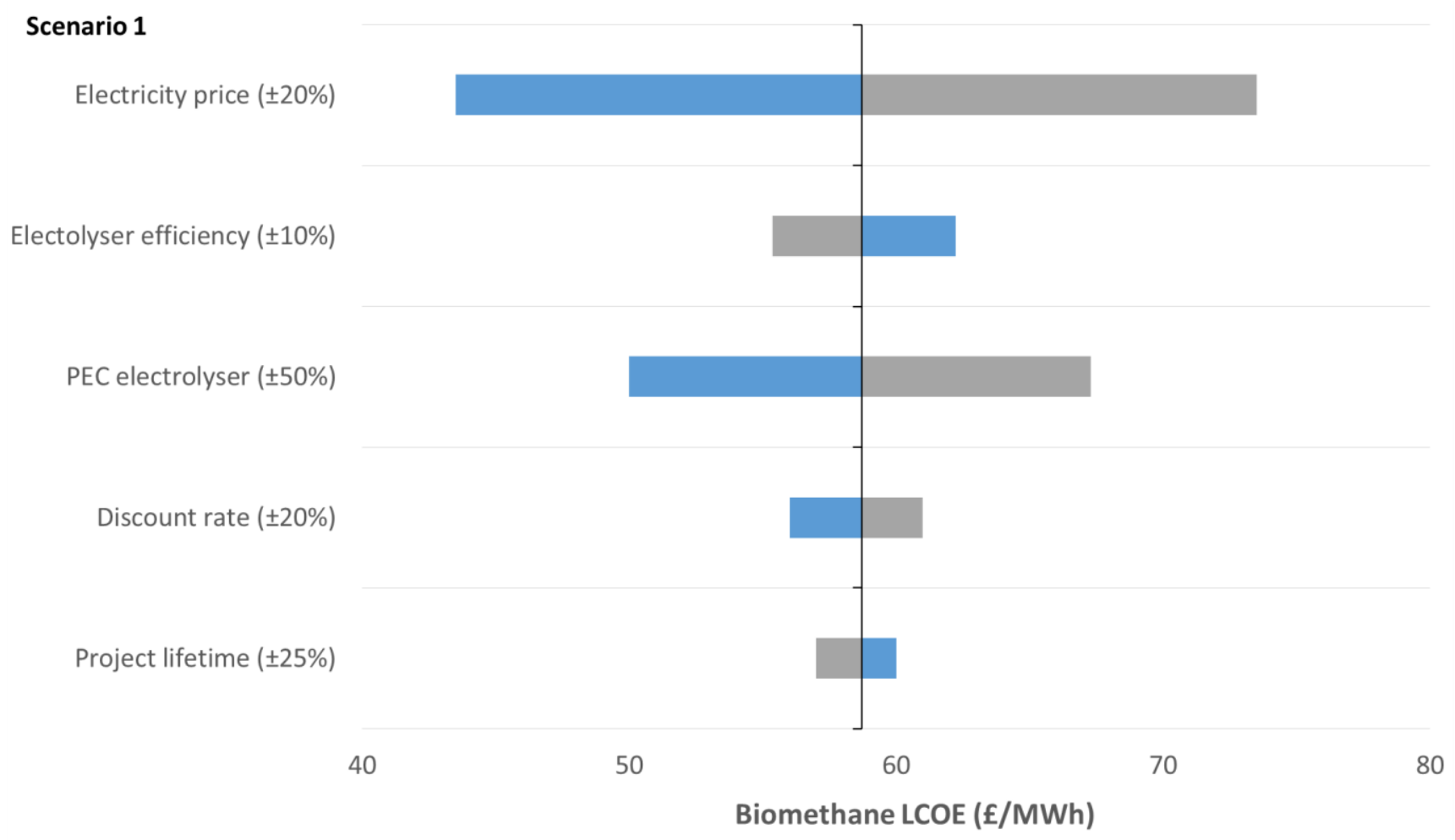




\section{Scenario 2}

Electricity price $( \pm 20 \%)$

Electolyser efficiency $( \pm 10 \%)$

PEC electrolyser ( $\pm 50 \%$ )

Discount rate $( \pm 20 \%)$

Project lifetime $( \pm 25 \%)$

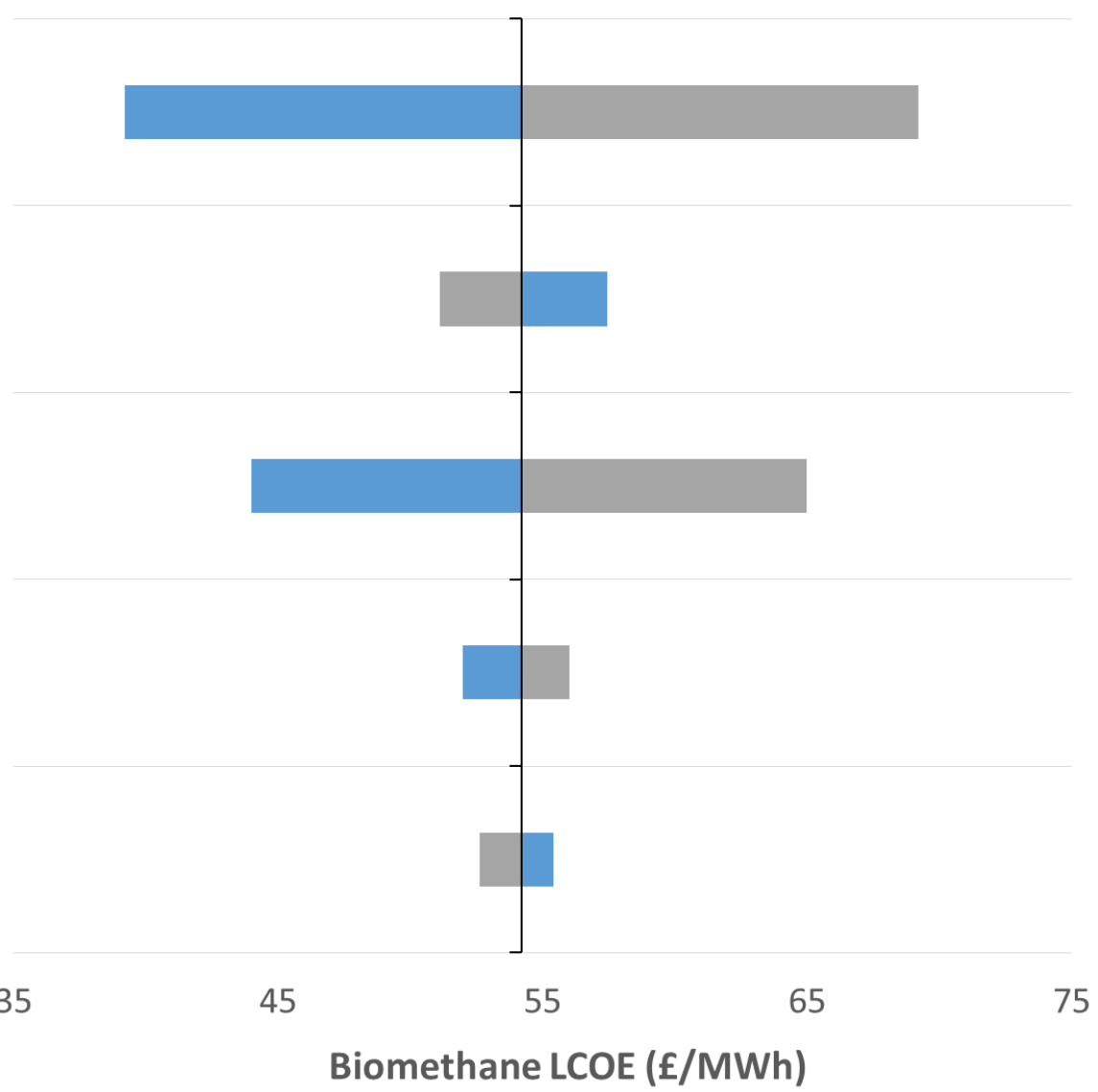

\section{Scenario 3}

Electricity price $( \pm 20 \%)$

Electolyser efficiency $( \pm 10 \%)$

PEC electrolyser $( \pm 50 \%)$

Discount rate $( \pm 20 \%)$

Project lifetime $( \pm 25 \%)$

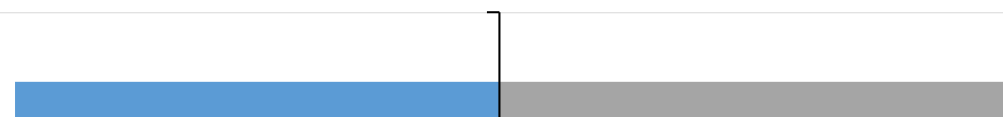




\section{Scenario 4}

Electricity price $( \pm 20 \%)$

Electolyser efficiency $( \pm 10 \%)$

PEC electrolyser $( \pm 50 \%)$

Discount rate $( \pm 20 \%)$

Project lifetime $( \pm 25 \%)$

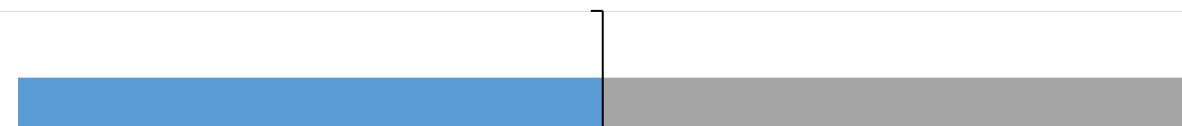

65

75

85

95

105

115

125

Biomethane LCOE (f/MWh)

\section{Scenario 5}

Electricity price $( \pm 20 \%)$

Electolyser efficiency $( \pm 10 \%)$

PEC electrolyser ( $\pm 50 \%)$

Discount rate $( \pm 20 \%)$

Project lifetime $( \pm 25 \%)$

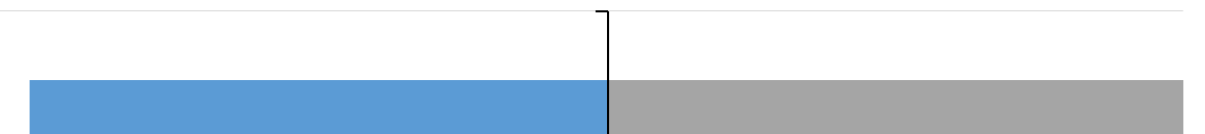

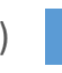

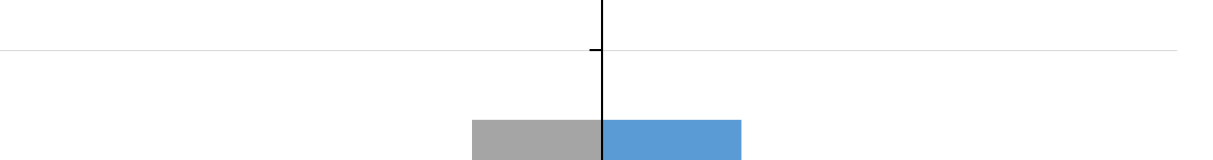


As depicted in Figure 12, the electricity price and the cost of the electrolyser raise the highest levels of uncertainty for all the scenarios. On the other hand, the influence of the electrolyser efficiency, the discount rate and the lifetime of the projects is remarkably lower. In an optimistic scenario, in which the accumulated positive effect of reduced electricity price and electrolyser cost, and increased electrolyser efficiency is assumed, the calculated LCOE for Scenarios 1-5 is 26.6, 24.8, 35.7, 36.5 and $37.8 \mathrm{f} / \mathrm{MWh}$. Figure 13 shows the performance of the investigated scenarios for different $\mathrm{CO}_{2}$ prices. It is observed that only Scenarios 1 and 2 can be competitive for reasonable $\mathrm{CO}_{2}$ prices; the Scenario 1 for carbon prices above $75 \mathrm{f} / \mathrm{t} \mathrm{CO} 2$ and the Scenario 2 for prices above $50 \mathrm{f} / \mathrm{tCO}_{2}$. It appears that insitu biomethanation is more favourable than ex-situ but the difference is too small to draw any reliable conclusion at this point. What is clear is that on-site renewable electricity generation (Scenarios 1 and 2 ) is a prerequisite for commercialisation. It would be ideal for new power to gas projects to not rely on the grid as grid prices are only expected to increase in contrast to renewable generation whereby significant reduction in generation costs are projected [63]. In addition, the procurement of green electricity ensures the low carbon footprint of the process and thus the eligibility for green incentives whereas the carbon footprint of the grid is location dependent and in most cases is still too carbonintensive to support power to gas projects.

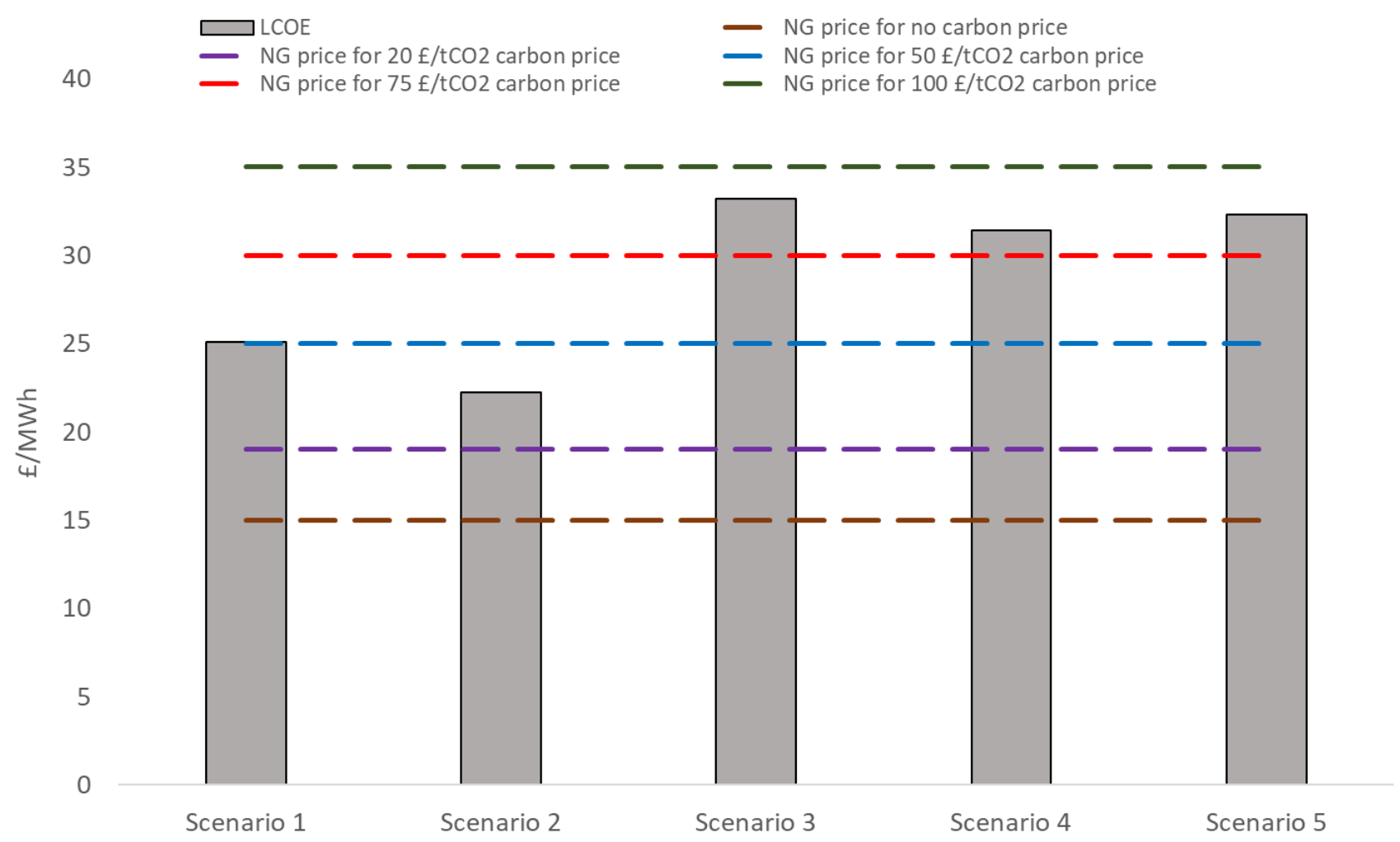

Figure 13. The optimistic LCOE for each case that includes projected techno-economic advances related to the electrolyser and reduced electricity prices against different carbon prices. 


\section{Conclusions}

Power to gas systems are considered technologies of the future with much debate being focussed on the potential techno-economic benefits. The current study detailed real life business scenarios in which the integration of biomethanation in an operating waste water plant is analysed.

The base case LCOE of the investigated scenarios lies between 127.8 and $159.8 \mathrm{f} / \mathrm{MWh}$. On considering existing policy schemes, tax exemptions and oxygen revenues, the LCOE experience a reduction that is between $57 \%$ and $75 \%$. Nevertheless, even under these optimistic conditions biomethane production is not competitive with the fossil natural gas supply. As revealed by the parametric analysis, the main bottleneck of the investigated scenarios are associated with the production of the electrolytic hydrogen and more specifically the electricity price and the electrolyser equipment cost. Short- to mid-term projections that include reduction in the electrolyser cost and the renewable energy generation, combined with an appropriate carbon price, i.e. 50-75 f/tcO create the right framework for the Scenarios 1 and 2 to generate profits.

The Scenarios 1 and 2 assume procurement of on-site wind electricity as opposed to the Scenarios 35 in which grid electricity is utilised. The study concluded that on-site generation should be considered a precondition for the implementation of power to gas technologies, as both prevailing and future costs are lower than the grid electricity prices. In addition, the carbon footprint of the wind generation can ensure the provision of renewable incentives.

Between in- and ex-situ biomethanation no clear conclusion can be drawn at the moment as the calculated lower capital cost of the in-situ can be offset by the fact that it has lower TRL. More research is required on the in-situ mainly on assessing possible mass transfer limitations that will enhance and inform scale-up efforts. Nonetheless, regardless the operational strategy biomethanation is a promising and efficient technology to upgrade biogas.

Overall, the current techno-economic environment for the successful implementation of power to gas infrastructures is still premature. As a future technology though, when the generation of electrolytic hydrogen will be competitive the integration of the biomethanation into power to gas systems is a sustainable solution that can decarbonise multiple sectors. It should be also noted that the implementation of long-term renewable schemes, such as the $\mathrm{RHI}$, is necessary not only for future but for also current applications. 


\section{References}

[1] Wu D, Li L, Zhao X, Peng Y, Yang P, Peng X. Anaerobic digestion: A review on process monitoring. Renew Sustain Energy Rev 2019;103:1-12. doi:https://doi.org/10.1016/j.rser.2018.12.039.

[2] Angelidaki I, Treu L, Tsapekos P, Luo G, Campanaro S, Wenzel H, et al. Biogas upgrading and utilization: Current status and perspectives. Biotechnol Adv 2018;36:452-66. doi:10.1016/j.biotechadv.2018.01.011.

[3] Miltner M, Makaruk A, Harasek M. Review on available biogas upgrading technologies and innovations towards advanced solutions. J Clean Prod 2017;161:1329-37. doi:https://doi.org/10.1016/j.jclepro.2017.06.045.

[4] Prussi M, Padella M, Conton M, Postma ED, Lonza L. Review of technologies for biomethane production and assessment of Eu transport share in 2030. J Clean Prod 2019;222:565-72. doi:https://doi.org/10.1016/j.jclepro.2019.02.271.

[5] Pöschl M, Ward S, Owende P. Evaluation of energy efficiency of various biogas production and utilization pathways. Appl Energy 2010;87:3305-21. doi:https://doi.org/10.1016/j.apenergy.2010.05.011.

[6] Hoyer K, Hulteberg C, Svensson M, Jernberg J, Norregard $\varnothing$. Biogas upgrading - Technical Review. 2016.

[7] Adnan Al, Ong MY, Nomanbhay S, Chew KW, Show PL. Technologies for Biogas Upgrading to Biomethane: A Review. Bioengineering 2019;6. doi:10.3390/bioengineering6040092.

[8] NGVA. Statistical Report 2017. 2018.

[9] Götz M, Lefebvre J, Mörs F, McDaniel Koch A, Graf F, Bajohr S, et al. Renewable Power-toGas: A technological and economic review. Renew Energy 2016;85:1371-90. doi:10.1016/j.renene.2015.07.066.

[10] Götz M, Koch A, Graf F. State of the Art and Perspectives of CO2 Methanation Process Concepts for Power-to-Gas Applications. Int. Gas Res. Conf. Proc., vol. 1, 2014.

[11] Bailera M, Lisbona P, Romeo LM, Espatolero S. Power to Gas projects review: Lab, pilot and demo plants for storing renewable energy and CO2. Renew Sustain Energy Rev 2017;69:292312. doi:https://doi.org/10.1016/j.rser.2016.11.130.

[12] Zimmermann AW, Wunderlich J, Müller L, Buchner GA, Marxen A, Michailos S, et al. TechnoEconomic Assessment Guidelines for CO2 Utilization. Front Energy Res 2020;8:5. doi:10.3389/fenrg.2020.00005.

[13] Zoss T, Dace E, Blumberga D. Modeling a power-to-renewable methane system for an assessment of power grid balancing options in the Baltic States' region. Appl Energy 2016;170:278-85. doi:10.1016/j.apenergy.2016.02.137.

[14] Jean MD Saint, Baurens P, Bouallou C. Parametric study of an efficient renewable power-tosubstitute-natural-gas process including high-temperature steam electrolysis. Int J Hydrogen Energy 2014;39:17024-39. doi:https://doi.org/10.1016/j.ijhydene.2014.08.091.

[15] Reiter G, Lindorfer J. Evaluating CO2 sources for power-to-gas applications - A case study for Austria. J CO2 Util 2015;10:40-9. doi:https://doi.org/10.1016/j.jcou.2015.03.003.

[16] Guandalini G, Campanari S, Romano MC. Power-to-gas plants and gas turbines for improved wind energy dispatchability: Energy and economic assessment. Appl Energy 2015;147:11730. doi:10.1016/j.apenergy.2015.02.055.

[17] McKenna RC, Bchini Q, Weinand JM, Michaelis J, König S, Köppel W, et al. The future role of Power-to-Gas in the energy transition: Regional and local techno-economic analyses in Baden-Württemberg. Appl Energy 2018;212:386-400. doi:10.1016/j.apenergy.2017.12.017.

[18] Parra D, Zhang X, Bauer C, Patel MK. An integrated techno-economic and life cycle environmental assessment of power-to-gas systems. Appl Energy 2017;193:440-54. doi:10.1016/j.apenergy.2017.02.063.

[19] Chiuta S, Engelbrecht N, Human G, Bessarabov DG. Techno-economic assessment of power- 
to-methane and power-to-syngas business models for sustainable carbon dioxide utilization in coal-to-liquid facilities. J CO2 Util 2016;16:399-411.

doi:https://doi.org/10.1016/j.jcou.2016.10.001.

[20] Vo TTQ, Wall DM, Ring D, Rajendran K, Murphy JD. Techno-economic analysis of biogas upgrading via amine scrubber, carbon capture and ex-situ methanation. Appl Energy 2018;212:1191-202. doi:10.1016/j.apenergy.2017.12.099.

[21] Van Dael M, Kreps S, Virag A, Kessels K, Remans K, Thomas D, et al. Techno-economic assessment of a microbial power-to-gas plant - Case study in Belgium. Appl Energy 2018;215:416-25. doi:10.1016/j.apenergy.2018.01.092.

[22] Michailos S, Walker M, Moody A, Poggio D, Pourkashanian M. Biomethane production using an integrated anaerobic digestion, gasification and $\mathrm{CO} 2$ biomethanation process in a real waste water treatment plant: A techno-economic assessment. Energy Convers Manag 2020;209:112663. doi:https://doi.org/10.1016/j.enconman.2020.112663.

[23] Kassem N, Hockey J, Lopez C, Lardon L, Angenent LT, Tester JW. Integrating anaerobic digestion $\{$, hydrothermal liquefaction $\{$, $\}$ and biomethanation within a power-to-gas framework for dairy waste management and grid decarbonization: a techno-economic assessment. Sustain Energy Fuels 2020;4:4644-61. doi:10.1039/D0SE00608D.

[24] Tao B, Alessi AM, Zhang Y, Chong JPJ, Heaven S, Banks CJ. Simultaneous biomethanisation of endogenous and imported $\mathrm{CO} 2$ in organically loaded anaerobic digesters. Appl Energy 2019;247:670-81. doi:https://doi.org/10.1016/j.apenergy.2019.04.058.

[25] Luo G, Angelidaki I. Hollow fiber membrane based H2 diffusion for efficient in situ biogas upgrading in an anaerobic reactor. Appl Microbiol Biotechnol 2013;97:3739-44. doi:10.1007/s00253-013-4811-3.

[26] Schmidt O, Gambhir A, Staffell I, Hawkes A, Nelson J, Few S. Future cost and performance of water electrolysis: An expert elicitation study. Int J Hydrogen Energy 2017;42:30470-92. doi:https://doi.org/10.1016/j.ijhydene.2017.10.045.

[27] Ravina M, Castellana C, Panepinto D, Zanetti MC. MCBioCH4: A computational model for biogas and biomethane evaluation. J Clean Prod 2019;227:739-47. doi:https://doi.org/10.1016/j.jclepro.2019.04.224.

[28] Porté H, Kougias PG, Alfaro N, Treu L, Campanaro S, Angelidaki I. Process performance and microbial community structure in thermophilic trickling biofilter reactors for biogas upgrading. Sci Total Environ 2019;655:529-38. doi:https://doi.org/10.1016/j.scitotenv.2018.11.289.

[29] Alfaro N, Fdz-Polanco M, Fdz-Polanco F, Díaz I. Evaluation of process performance, energy consumption and microbiota characterization in a ceramic membrane bioreactor for ex-situ biomethanation of $\mathrm{H} 2$ and CO2. Bioresour Technol 2018;258:142-50. doi:https://doi.org/10.1016/j.biortech.2018.02.087.

[30] Rachbauer L, Voitl G, Bochmann G, Fuchs W. Biological biogas upgrading capacity of a hydrogenotrophic community in a trickle-bed reactor. Appl Energy 2016;180:483-90. doi:https://doi.org/10.1016/j.apenergy.2016.07.109.

[31] Albrecht FG, König DH, Baucks N, Dietrich R-U. A standardized methodology for the technoeconomic evaluation of alternative fuels - A case study. Fuel 2017;194:511-26. doi:https://doi.org/10.1016/j.fuel.2016.12.003.

[32] Nord Pool. UK Day Ahead Auction Prices n.d. https://www.nordpoolgroup.com/Marketdata1/GB/Auction-prices/UK/Hourly/?view=table.

[33] Liso V, Savoia G, Araya SS, Cinti G, Kær SK. Modelling and Experimental Analysis of a Polymer Electrolyte Membrane Water Electrolysis Cell at Different Operating Temperatures. Energies 2018;11. doi:10.3390/en11123273.

[34] Michailos S, McCord S, Sick V, Stokes G, Styring P. Dimethyl ether synthesis via captured CO2 hydrogenation within the power to liquids concept: A techno-economic assessment. Energy Convers Manag 2019;184:262-76. doi:10.1016/j.enconman.2019.01.046. 
[35] Bekkering J, Zwart K, Martinus G, Langerak J, Tideman J, van der Meij T, et al. Farm-scale biopower-to-methane: Comparative analyses of economic and environmental feasibility. Int J Energy Res 2020;44:2264-77. doi:10.1002/er.5093.

[36] Graf F, Krajete A, Schmack U. Techno-ökonomische Studie zur biologischen Methanisierung bei Power-to-Gas-Konzepten. 2014. doi:10.13140/RG.2.1.2001.9366.

[37] Dimitriou I, Goldingay H, Bridgwater A V. Techno-economic and uncertainty analysis of Biomass to Liquid (BTL) systems for transport fuel production. Renew Sustain Energy Rev 2018;88:160-75. doi:10.1016/j.rser.2018.02.023.

[38] Towler G, Sinnott R. Chapter 7 - Capital Cost Estimating. In: Towler G, Sinnott R, editors. Chem. Eng. Des. (Second Ed. Second Edi, Boston: Butterworth-Heinemann; 2013, p. 307-54. doi:https://doi.org/10.1016/B978-0-08-096659-5.00007-9.

[39] Haro P, Johnsson F, Thunman H. Improved syngas processing for enhanced Bio-SNG production: A techno-economic assessment. Energy 2016;101:380-9. doi:10.1016/j.energy.2016.02.037.

[40] Turley D, Hopwood L, Burns C, Maio D Di. Assessment of digestate drying as an eligible heat use. n.d.

[41] Albrecht FG, König DH, Baucks N, Dietrich RU. A standardized methodology for the technoeconomic evaluation of alternative fuels - A case study. Fuel 2017;194:511-26. doi:10.1016/j.fuel.2016.12.003.

[42] Bellotti D, Rivarolo M, Magistri L. Economic feasibility of methanol synthesis as a method for CO2 reduction and energy storage. Energy Procedia 2019;158:4721-8. doi:https://doi.org/10.1016/j.egypro.2019.01.730.

[43] Kuckshinrichs W, Ketelaer T, Koj JC. Economic Analysis of Improved Alkaline Water Electrolysis. Front Energy Res 2017;5:1. doi:10.3389/fenrg.2017.00001.

[44] Pääkkönen A, Tolvanen H, Rintala J. Techno-economic analysis of a power to biogas system operated based on fluctuating electricity price. Renew Energy 2018;117:166-74. doi:10.1016/j.renene.2017.10.031.

[45] Towler G, Sinnott R. Chapter 8 - Estimating Revenues and Production Costs. In: Towler G, Sinnott R, editors. Chem. Eng. Des. (Second Ed. Second Edi, Boston: Butterworth-Heinemann; 2013, p. 355-87. doi:https://doi.org/10.1016/B978-0-08-096659-5.00008-0.

[46] Peters MS, Timmerhaus KD. Plant design and economics for chemical engineers. McGraw-Hill; 1991.

[47] Colella WG, James BD, Moton JM, Saur G, Ramsden T. Techno-economic Analysis of PEM Electrolysis for Hydrogen Production. Electrolytic Hydrog. Prod. Work. NREL, Golden, Color. 27 Febr. 2014, n.d.

[48] Office for National Statistics. A01: Summary of labour market statistics n.d. https://www.ons.gov.uk/employmentandlabourmarket/peopleinwork/employmentandempl oyeetypes/datasets/summaryoflabourmarketstatistics.

[49] GOV.UK. Sector, Gas and electricity prices in the non-domestic 2019. https://www.gov.uk/government/statistical-data-sets/gas-and-electricity-prices-in-the-nondomestic-sector.

[50] Department for Business, Energy and Industrial Strategy. Electricity generation costs. 2016.

[51] Eurostat. Electricity prices. n.d. https://ec.europa.eu/eurostat/web/energy/data/database.

[52] Breyer C, Tsupari E, Tikka V, Vainikka P. Power-to-Gas as an Emerging Profitable Business Through Creating an Integrated Value Chain. Energy Procedia 2015;73:182-9. doi:https://doi.org/10.1016/j.egypro.2015.07.668.

[53] Buttler A, Spliethoff H. Current status of water electrolysis for energy storage, grid balancing and sector coupling via power-to-gas and power-to-liquids: A review. Renew Sustain Energy Rev 2018;82:2440-54. doi:https://doi.org/10.1016/j.rser.2017.09.003.

[54] McDonagh S, O'Shea R, Wall DM, Deane JP, Murphy JD. Modelling of a power-to-gas system to predict the levelised cost of energy of an advanced renewable gaseous transport fuel. Appl 
Energy 2018;215:444-56. doi:https://doi.org/10.1016/j.apenergy.2018.02.019.

[55] Ofgem. Non-Domestic Renewable Heat Incentive. Sustainability Self-Reporting Guidance (version 2). 2018.

[56] Zhang X, Witte J, Schildhauer T, Bauer C. Life cycle assessment of power-to-gas with biogas as the carbon source. Sustain Energy Fuels 2020. doi:10.1039/C9SE00986H.

[57] Greenhouse gas reporting: conversion factors 2018, GOV.UK n.d. https://www.gov.uk/government/publications/greenhouse-gas-reporting-conversion-factors2018.

[58] Albrecht FG, Nguyen T-V. Prospects of electrofuels to defossilize transportation in Denmark A techno-economic and ecological analysis. Energy 2019:116511.

doi:https://doi.org/10.1016/j.energy.2019.116511.

[59] The Department for Business, Energy \& Industrial Strategy (BEIS). UPDATED ENERGY AND EMISSIONS PROJECTIONS 2018. 2019.

[60] The Future of UK Carbon Pricing. 2019.

[61] No Title n.d. https://sandbag.org.uk/.

[62] Smolinka T, Thomassen M, Oyarce A, Marchal F. MEGASTACK: Stack Design for a Megawatt Scale PEM Electrolyser. D.1.1 Cost benefit analysis and cost and performance target for large scale PEM electrolyser stack. 2016.

[63] BEIS. Electricity Generating Costs. 2016. doi:267393///1/1 25 May 2010.

\section{Acknowledgements}

The authors would like to acknowledge the Engineering and Physical Sciences Research Council (EPSRC) for the support of the IBCat H2AD project. In addition, the contribution of United Utilities is much acknowledged and appreciated. 



\section{Appendix A - Economic data and methodologies}

Table A.1. Equipment cost data

\begin{tabular}{|c|c|c|c|c|c|c|c|}
\hline Equipment & Base cost (Mf) & Design Variable & Base capacity & Unit & Scaling factor & Base year & Ref \\
\hline $\mathrm{H}_{2}$ injection system* & \multicolumn{6}{|c|}{$1 \%$ of the electrolyser PEC } & Assumption \\
\hline Biomethanation reactor & 1.97 & $\mathrm{MW}_{\mathrm{th}, \mathrm{CH} 4}$ & 5 & $\mathrm{MW}$ & 0.7 & 2016 & {$[20]$} \\
\hline Digestate dewatering & 0.105 & Digestate flow & 10,000 & $\mathrm{t} / \mathrm{y}$ & 0.7 & 2015 & {$[40]$} \\
\hline ZnO guard bed & 0.016 & Gas flow & 8 & $\mathrm{~m}^{3} / \mathrm{s}$ & 1 & 2014 & [41] \\
\hline Pumps & 0.0806 & Power & 10 & $\mathrm{~m}^{3} / \mathrm{s}$ & 0.36 & 2014 & [41] \\
\hline PEMEL** & 1.044 & Installed capacity & 1 & MWe & 0.85 & 2017 & {$[42]$} \\
\hline $\mathrm{AEL}^{* *}$ & 0.617 & Installed capacity & 1 & MWe & 0.85 & 2015 & {$[43]$} \\
\hline $\mathrm{H}_{2}$ buffer storage & \multicolumn{6}{|c|}{ Cost $=a+b S^{n}$, where $a=5800, b=1600, n=0.7$ and $S$ is the size of the tank in $\mathrm{m}^{3}$} & [44] \\
\hline
\end{tabular}

Table A.2. Methodology for fixed costs [43][45][46][47]

\begin{tabular}{ll}
\hline Parameter & Price \\
\hline Supervision & $0.25 \times$ Labour \\
Direct overhead & $0.5 \times($ Labour + supervision) \\
General overhead & $0.5 \times($ Labour + supervision + direct overhead) \\
Maintenance Labour & $0.015 \times \mathrm{FCl}$ \\
Maintenance materials & $0.015 \times \mathrm{FCl}$ \\
Insurance and tax & $0.01 \times \mathrm{FCl}$ \\
Replacement cost of the PEMEL (\% of the & 12 \\
DC; applied after 10 years) & \\
Replacement cost of the AEL (\% of the PEC; & 50 \\
applied after 10 years) & \\
Financing working capital & Discount rate $\times$ WC \\
\hline
\end{tabular}

